University of Wisconsin Milwaukee

UWM Digital Commons

Geosciences Faculty Articles

Geosciences

$1-1-2009$

\title{
Magnetic and petrologic characterization of synthetic Martian basalts and implications for the surface magnetization of Mars
}

Julie A. Bowles

University of Wisconsin-Milwaukee, bowlesj@uwm.edu

Julie E. Hammer

University of Hawaii, Manoa

Stefanie A. Brachfeld

Montclair State University, brachfelds@mail.montclair.edu

Follow this and additional works at: https://dc.uwm.edu/geosci_facart

Part of the Earth Sciences Commons

\section{Recommended Citation}

Bowles, Julie A.; Hammer, Julie E.; and Brachfeld, Stefanie A., "Magnetic and petrologic characterization of synthetic Martian basalts and implications for the surface magnetization of Mars" (2009). Geosciences Faculty Articles. 3.

https://dc.uwm.edu/geosci_facart/3

This Article is brought to you for free and open access by UWM Digital Commons. It has been accepted for inclusion in Geosciences Faculty Articles by an authorized administrator of UWM Digital Commons. For more information, please contact open-access@uwm.edu. 


\title{
Magnetic and petrologic characterization of synthetic Martian basalts and implications for the surface magnetization of Mars
}

\author{
Julie A. Bowles, ${ }^{1,2}$ Julia E. Hammer, ${ }^{1}$ and Stefanie A. Brachfeld ${ }^{3}$ \\ Received 12 March 2009; revised 25 May 2009; accepted 24 June 2009; published 16 October 2009.
}

[1] A suite of synthetic Martian basalts is generated with the objective of providing fundamental material properties data for use in modeling and interpretation of mission data. We systematically evaluate the effects of major element composition, oxygen fugacity $\left(f \mathrm{O}_{2}\right)$, and cooling rate on phase chemistry and magnetic mineralogy, grain size, and intensity of remanent magnetization. The range of experimental compositions and $f \mathrm{O}_{2}$ are chosen to bracket the range expected in the Martian crust; our results should therefore span the range of possible mineralogies, textures, and magnetic properties in rapidly cooled Mars crustal materials. Two starting compositions are used for the sample synthesis: (1) an Fe-rich, Al-poor composition patterned after SNC basaltic meteorites and (2) a composition based on thermal emission spectrometer (TES) data with a much lower $\mathrm{Fe} / \mathrm{Al}$ ratio. The resulting magnetic phase in samples generated at the quartz-fayalitemagnetite (QFM) buffer is a spinel-structured oxide with varying amounts of $\mathrm{Cr}, \mathrm{Ti}, \mathrm{Mg}$, and Al. Compositional differences depend on bulk composition, cooling rate, differences in crystallization sequence, and the kinetics of silicate mineral nucleation and growth. Oxide abundance and magnetic intensity are most strongly influenced by $f \mathrm{O}_{2}$, with more subtle composition and cooling rate effects. Moderately oxidizing QFM conditions result in an intense magnetization $\left(2.3 \times 10^{-5} \mathrm{Am}^{2} \mathrm{~kg}^{-1}\right.$ to $\left.1.4 \times 10^{-2} \mathrm{Am}^{2} \mathrm{~kg}^{-1}\right)$, especially in the meteorite-derived basalts. However, an increase of magnetic grain size into the multidomain range (meteorite-type) and/or low unblocking temperatures resulting from increased $\mathrm{Cr}$ substitution (TES-type) may affect the long-term stability of the remanence in QFM samples.

Citation: Bowles, J. A., J. E. Hammer, and S. A. Brachfeld (2009), Magnetic and petrologic characterization of synthetic Martian basalts and implications for the surface magnetization of Mars, J. Geophys. Res., 114, E10003, doi:10.1029/2009JE003378.

\section{Introduction}

[2] The strong intensity of the Martian magnetic anomalies mapped by the Mars Global Surveyor (MGS) has led to considerable interest in the magnetization of the Martian crust. The strongly magnetic crust is limited largely to the ancient $(>4 \mathrm{Ga})$, cratered, southern highlands, and the standard interpretation holds that the crust was magnetized in the presence of a Martian dynamo that was active early in the planet's history [e.g., Stevenson, 2001]. A growing body of work seeks to further explain the patterns of magnetization [Johnson and Phillips, 2005; Nimmo, 2000; Stanley et al., 2008; Hood et al., 2007], as well as a magnetic mineral assemblage capable of producing a magnetization inferred to be several orders of magnitude stronger than typical terrestrial basalt [Connerney et al., 1999].

\footnotetext{
${ }^{1}$ Department of Geology and Geophysics, University of Hawai'i at Mānoa, Honolulu, Hawaii, USA.

${ }^{2}$ Now at Institute for Rock Magnetism, University of Minnesota, Minneapolis, Minnesota, USA.

${ }^{3}$ Department of Earth and Environmental Studies, Montclair State University, Upper Montclair, New Jersey, USA.
}

Copyright 2009 by the American Geophysical Union. 0148-0227/09/2009JE003378\$09.00
[3] Most rock magnetic studies have focused on the magnetic mineralogy of the geologically youthful $(<1.2 \mathrm{Ga})$ SNC meteorites, which postdate cessation of the Martian geodynamo and are inferred to be from the northern lowlands. Magnetic remanence carriers in these meteorites include pyrrhotite, (titano)magnetite, and chromite [Rochette et al., 2005, and references therein; Yu and Gee, 2005]. At least two meteorites have been found to contain metallic iron inclusions within olivine crystals, an inferred shockinduced reduction product [Van de Moortèle et al., 2007]. Of the SNC meteorites, typically only the nakhlites (clinopyroxeneites) and some basaltic shergottites are capable of acquiring a remanence intense enough to produce anomalies of sufficient magnitude [Rochette et al., 2005].

[4] Because the magnetic anomalies are largely limited to the more ancient southern highlands, these young meteorites may be atypical of the magnetized crust. Mineral phases not observed in meteorites have therefore also been proposed, including multidomain hematite [Kletetschka et al., 2000; Dunlop and Kletetschka, 2001]; olivine-hosted magnetite inclusions [Gunnlaugsson et al., 2006]; and hematiteilmenite intergrowths [McEnroe et al., 2002; Brown and McEnroe, 2008] or some other two-phase intergrowth [Hargraves et al., 2001]. 
Table 1. Bulk Compositions and CIPW Normative Mineralogy

\begin{tabular}{|c|c|c|c|c|c|c|c|c|}
\hline & \multicolumn{4}{|c|}{ Meteorite Type } & \multicolumn{3}{|c|}{ TES Type } & \multirow[b]{2}{*}{ Backstay $^{\mathrm{f}}$} \\
\hline & $\mathrm{A}^{* \mathrm{a}}$ & $\mathrm{A}^{*} \bmod ^{\mathrm{b}}$ & Batch $1^{\mathrm{c}}$ & Batch $2^{\mathrm{c}}$ & $\mathrm{B} 2^{\mathrm{d}}$ & Batch $1^{\mathrm{c}}$ & Batch $2^{\mathrm{e}}$ & \\
\hline $\mathrm{SiO}_{2}$ & 51.40 & 51.16 & 54.20 & 52.71 & 51.20 & 51.21 & 46.97 & 50.16 \\
\hline $\mathrm{TiO}_{2}$ & 1.63 & 1.61 & 1.50 & 1.61 & 1.60 & 1.64 & 1.93 & 0.94 \\
\hline $\mathrm{Al}_{2} \mathrm{O}_{3}$ & 9.13 & 8.70 & 7.97 & 7.66 & 17.01 & 16.81 & 17.96 & 13.45 \\
\hline $\mathrm{FeO}^{*}$ & 18.90 & 18.90 & 17.38 & 18.14 & 8.48 & 8.69 & 8.54 & 13.85 \\
\hline $\mathrm{MgO}$ & 7.27 & 7.04 & 6.71 & 7.54 & 7.04 & 7.09 & 8.61 & 8.41 \\
\hline $\mathrm{CaO}$ & 8.77 & 8.44 & 7.90 & 8.35 & 10.50 & 10.68 & 11.35 & 6.11 \\
\hline $\mathrm{Na}_{2} \mathrm{O}$ & 2.13 & 2.28 & 2.65 & 2.57 & 2.28 & 2.18 & 2.84 & 4.20 \\
\hline $\mathrm{K}_{2} \mathrm{O}$ & 0.75 & 0.76 & 0.77 & 0.67 & 0.76 & 0.70 & 0.79 & 1.08 \\
\hline $\mathrm{P}_{2} \mathrm{O}_{5}$ & 0.49 & 0.50 & 0.46 & 0.33 & 0.50 & 0.50 & 0.56 & 1.41 \\
\hline $\mathrm{MnO}$ & - & 0.53 & 0.37 & 0.43 & 0.53 & 0.43 & 0.44 & 0.24 \\
\hline $\mathrm{Cr}_{2} \mathrm{O}_{3}$ & - & 0.10 & 0.09 & not measured ${ }^{\mathrm{g}}$ & 0.10 & 0.09 & not measured ${ }^{\mathrm{g}}$ & 0.15 \\
\hline $\mathrm{Fe} / \mathrm{Al}$ & 1.50 & 1.50 & 1.50 & 1.70 & 0.35 & 0.37 & 0.34 & 0.73 \\
\hline \multicolumn{9}{|l|}{ Normative mineralogy ${ }^{\mathrm{h}}$} \\
\hline Quartz & 4.48 & 4.10 & 7.65 & 4.88 & 2.27 & 2.78 & 0.00 & 0.00 \\
\hline Total feldspar/feldspathoid & 35.25 & 34.86 & 34.39 & 32.89 & 57.60 & 56.47 & 60.76 & 56.0 \\
\hline Total pyroxene & 49.26 & 49.78 & 47.53 & 51.48 & 33.32 & 33.82 & 15.03 & 17.2 \\
\hline Olivine & 0.00 & 0.00 & 0.00 & 0.00 & 0.00 & 0.00 & 16.41 & 16.0 \\
\hline Apatite & 1.15 & 1.18 & 1.08 & 0.78 & 1.18 & 1.18 & 1.32 & 3.3 \\
\hline Ilmenite & 3.07 & 3.04 & 2.84 & 3.04 & 3.03 & 3.11 & 3.65 & 1.8 \\
\hline Magnetite & 6.80 & 7.05 & 6.51 & 6.93 & 2.60 & 2.64 & 2.83 & 4.8 \\
\hline
\end{tabular}

${ }^{\mathrm{a}} \mathrm{SNC}-\mathrm{like}$ composition used by Hammer [2006] and Brachfeld and Hammer [2006].

${ }^{\mathrm{b}}$ Desired SNC-like composition used in present study which includes $\mathrm{Mn}$ and $\mathrm{Cr}$.

${ }^{c}$ Measured bulk composition of glass quenched from $>\mathrm{T}_{\mathrm{L}}$

${ }^{\mathrm{d}}$ Desired Earth-like composition used in present study.

${ }^{\mathrm{e}}$ Measured bulk composition of glass quenched from $>\mathrm{T}_{\mathrm{L}}$. Note that the $\mathrm{SiO}_{2}$ content of Batch 2 was considerably lower than desired, resulting in a melt that is olivine normative rather than quartz normative. It is possible this had an effect on the silicate phases present, although it is not obvious in the experimental results. It is unlikely to play a significant role in the abundance or composition of oxide phases.

${ }^{\mathrm{f}}$ McSween et al. [2006], as reproduced in the work by Nekvasil et al. [2009].

${ }^{\mathrm{g}}$ Did not analyze for Cr.

${ }^{\mathrm{h}} \mathrm{FeO}$ and $\mathrm{Fe}_{2} \mathrm{O}_{3}$ were computed from FeO* using method of Kilinc et al. [1983] and assuming $1200^{\circ} \mathrm{C}$ and $f \mathrm{O}_{2}$ controlled by the QFM buffer in order to perform the CIPW norm calculation. Normative mineralogy for Backstay from McSween et al. [2006].

[5] While both shock [Van de Moortèle et al., 2007] and hydrothermal alteration [Scott and Fuller, 2004] have been suggested to explain the intense magnetization, most theories posit that the anomalies represent a primary thermal remanence acquired by igneous rocks cooling in presence of a dynamo field. This in part has motivated us to explore what conditions might be necessary to produce a strong, stable magnetic carrier in a solidifying Martian crust. We take an experimental approach, synthesizing basalts of expected Martian compositions, while varying cooling rate, oxygen fugacity $\left(f \mathrm{O}_{2}\right)$, and major element composition. This allows us to place constraints on conditions that could plausibly result in strong, stable magnetic remanence, and provides fundamental material properties for use in modeling and interpretation of mission data.

[6] Our work builds upon that of Hammer [2006] and Brachfeld and Hammer [2006] where a synthetic, Fe-rich basalt (patterned after the basaltic meteorites) was crystallized over a wide range of $f \mathrm{O}_{2}$ and cooling rates, and the resulting magnetic assemblage was examined. In this work, we expand the range of compositions to include a basalt with a much lower $\mathrm{Fe} / \mathrm{Al}$ ratio, on the basis of satellite thermal emission spectrometer (TES) observations of the southern highlands that suggest a composition more closely resembling terrestrial basalt [Hamilton et al., 2001]. We also add the minor elements $\mathrm{Mn}$ and $\mathrm{Cr}$ to both the Fe-rich and $\mathrm{Fe}$-poor basalt, in light of evidence that $\mathrm{Cr}-\mathrm{Fe}-\mathrm{Ti}$ oxides can carry a magnetic remanence in Martian meteorites $[Y u$ and Gee, 2005; Weiss et al., 2002]. Compared to Hammer [2006], we restrict the range of $f \mathrm{O}_{2}$ to that between the iron-wüstite (IW) buffer and the quartz-fayalite-magnetite (QFM) buffer. This allows us to explore in more detail the $f \mathrm{O}_{2}$ range most commonly found for basaltic meteorites [Herd et al., 2002; Wadhwa, 2008], as well as the range over which a dramatic change in both oxide abundance and magnetic properties occurs [Brachfeld and Hammer, 2006].

[7] We continue to focus on controlled, relatively rapid cooling as a mechanism for production of a single-domain magnetic carrier, which is likely to produce a stronger and more stable remanence than multidomain carriers. These experiments, therefore, are most relevant to models whereby the upper crust of Mars is produced through repeated volcanic extrusion [Zhong and Roberts, 2003; ArkaniHamed, 2005] or dike injection [Nimmo, 2000].

\section{Methods}

\subsection{Starting Material Selection}

[8] Two starting compositions (Table 1) are used for the sample synthesis. The first composition is Fe-rich and Al-poor (atoms $\mathrm{Fe} / \mathrm{Al}=1.5$ ) and is patterned after the widely recognized Fe-rich, Al-poor character of SNC parent melts [e.g., Johnson et al., 1991; Treiman, 1993; McSween, 2007]. It is similar in composition to that used by Hammer [2006] and Brachfeld and Hammer [2006], but includes small amounts of $\mathrm{Mn}$ and $\mathrm{Cr}$. The second composition is identical to the first in all respects save $\mathrm{Fe}$ (in which the second composition is poorer), $\mathrm{Al}$ (richer), and $\mathrm{Ca}$ (slightly richer). The relative abundances of $\mathrm{Fe}$ and $\mathrm{Al}$ in the second composition $(\mathrm{Fe} / \mathrm{Al}=0.4)$ typify those of terrestrial basalt 
[e.g., Leeman et al., 1990; Flower et al., 1982] and satisfy compositional constraints posed by deconvolved thermal emission spectrometer (TES) data from the Mars surface [e.g., Hamilton et al., 2001]. Some experimentalists have also proposed that moderate-Fe/Al basalts are parental to Mars meteorite materials [Nekvasil et al., 2007]. Thus, the experimental starting compositions synthesized here bracket the range of compositions that have been proposed as relevant mafic igneous materials on Mars.

[9] The first composition $(\mathrm{Fe} / \mathrm{Al}=1.5)$ will hereafter be referred to as the "meteorite-type" or "M-type" composition, while the second $(\mathrm{Fe} / \mathrm{Al}=0.4)$ will be referred to as the "TES-type" or "T-type" composition.

[10] The CIPW normative mineralogies (Table 1) and rheologies of the M-type and T-type target starting materials differ in important ways. Key differences include (1) the inverse relationship between feldspar and pyroxene contents, with 35 and 50 wt. \%, respectively, in the M-type composition, and $\sim 60$ and 35 wt. $\%$, respectively, in the T-type composition; (2) the normative magnetite content of the M-type material more than twice that of T-type material; and (3) a melt viscosity more than 1 order of magnitude greater in T-type melt compared to M-type melt (using method of Shaw [1972]), at a given temperature.

[11] Differences in the major element composition of the two starting materials lead to contrasting liquid lines of descent during equilibrium fractional crystallization as computed using the MELTS algorithm [Ghiorso and Sack, 1995]. Consistent with the CIPW norm calculation, the mineral-in sequence at QFM in the M-type liquid is spinel oxide, clinopyroxene, feldspar, and olivine; the T-type liquid begins with spinel oxide, followed by feldspar, olivine, and clinopyroxene. Similar trends are computed for reducing conditions, with a key difference being the increase in the olivine-in temperature (becoming the liquidus phase) and greater modal proportion of olivine in M-type material with decreasing $f \mathrm{O}_{2}$.

\subsection{Sample Synthesis}

[12] Samples were synthesized from powdered oxide, carbonate, and phosphate reagents. This was done twice for each composition, as we ran out of the first batch midway through the experiments. Slight differences in the resulting bulk composition are noted in Table 1. Oxygen fugacity was maintained in one of the following two ways.

[13] 1. Sample powder mixtures intended for treatment at QFM and some intended for IW were first heated at $925^{\circ} \mathrm{C}$ in a controlled $f \mathrm{O}_{2}$ atmosphere using flowing $\mathrm{H}_{2}-\mathrm{CO}_{2}$ to impart an intrinsic $\mathrm{fO}_{2}$. Approximately $0.3 \mathrm{~g}$ of the mixture was then placed in a Pt capsule, which was sealed in an evacuated Si tube along with a solid state buffer assemblage to monitor departure from the desired $f \mathrm{O}_{2}$. QFM samples at cooling rates $\leq 19^{\circ} \mathrm{C} \mathrm{h}^{-1}$ were sealed in double-walled $\mathrm{Si}$ tubes, on the basis of results from Hammer [2006] showing unintended oxidation to the magnetite-hematite buffer.

[14] 2. Some samples to be treated at IW and all at intermediate $f \mathrm{O}_{2}$ were heated to $925^{\circ} \mathrm{C}$ in an arbitrary atmosphere to decarbonate the sample powder mixtures. About $0.3 \mathrm{~g}$ of the decarbonated sample mixture was then pressed into a pellet and was suspended on a $\mathrm{Pt}$ wire spiral to be heated above the liquidus $\left(\mathrm{T}_{\mathrm{L}}\right)$ under flowing $\mathrm{H}_{2}-\mathrm{CO}_{2}$.
[15] In both scenarios, $f \mathrm{O}_{2}$ during flowing gas treatment was monitored with a solid zirconia electrolyte oxygen sensor. Temperature directly adjacent to the sample was measured with a Pt-Rh thermocouple.

[16] To address the issue of iron loss into the Pt capsule or $\mathrm{Pt}$ wire, capsules to be used at $f \mathrm{O}_{2} \geq \mathrm{IW}+2 \log _{10}$ units were run first with the sample material at $\mathrm{T}_{\mathrm{L}}+5^{\circ} \mathrm{C}$ for $18 \mathrm{~h}$ and then quenched. The solidified sample was discarded and this procedure was repeated one or more times [e.g., Hammer, 2006]. Because Fe loss increases at decreasing $f \mathrm{O}_{2}$, a more aggressive approach was used for samples run at IW. The equilibrium mole fraction of $\mathrm{Fe}$ in the $\mathrm{Pt}$ $\left(\mathrm{X}^{\mathrm{Fe}}\right)$ was calculated using the equations of Kessel et al. [2001] for temperatures just below the liquidus. The Pt was then packed in $\mathrm{Fe}_{2} \mathrm{O}_{3}$ powder and held at the temperature and $\mathrm{fO}_{2}$ determined to produce the desired $\mathrm{X}^{\mathrm{Fe}}$ [Kessel et $a l ., 2001]$. Because wüstite $(\mathrm{FeO})$ adhered to the Pt following this treatment and had to be abraded away, it was impossible to determine the precise value of $\mathrm{X}^{\mathrm{Fe}}$ via weighing, but we estimate that $\mathrm{X}^{\mathrm{Fe}}$ is within $\sim 20 \%$ of the desired value.

[17] Most samples were heated to $\sim 5-10^{\circ} \mathrm{C}$ above $\mathrm{T}_{\mathrm{L}}$ as calculated the MELTS algorithm [Ghiorso and Sack, 1995] and were held at this temperature for 4-6 h. Alternatively, a few samples were heated to $\sim \mathrm{T}_{\mathrm{L}}+25^{\circ} \mathrm{C}$ and were cooled at $2^{\circ} \mathrm{C} \mathrm{h}^{-1}$ to $\mathrm{T}_{\mathrm{L}}+5^{\circ} \mathrm{C}$ where they were held for $4 \mathrm{~h}$. Samples were then cooled to $400-600^{\circ} \mathrm{C}$ at constant cooling rates ranging from $231^{\circ} \mathrm{C} \mathrm{h}^{-1}$ to $5.7^{\circ} \mathrm{C} \mathrm{h}^{-1}$ using a programmable temperature controller. In addition, an exponentially varying cooling rate was also applied to QFM samples to simulate the natural cooling path of a conductively cooling lava flow at $\sim 0.25 \mathrm{~m}$ from its surface [Turcotte and Schubert, 2002]. Cooling rates during this experiment varied from $53^{\circ} \mathrm{C} \mathrm{h}^{-1}$ at high temperatures to $2^{\circ} \mathrm{C} \mathrm{h}^{-1}$ at the lowest temperatures.

[18] Following sample synthesis, splits of the recovered material were used for compositional, petrographic and magnetic analyses.

\subsection{Compositional and Petrographic Analyses}

[19] Electron backscatter images and nonquantitative EDS constraints on mineral compositions were acquired with a JEOL J5900 scanning electron microscope (SEM) at University of Hawaii. Compositional information on the largest oxide crystals was obtained using a Cameca SX-100 electron microprobe (EMP) at University of Oregon.

[20] Low totals were consistently observed on the EMP analyses, and it was ultimately determined that this resulted both from a carbon coating thicker than that used on the calibration standards and (to a lesser extent and in the smallest grains only) an interaction volume larger than the grain size. Some samples were measured again after reapplying an appropriate carbon coat. After recoating, analysis totals were near $100 \%$, assuming 4 oxygen per 3 cations (spinel structure). If analyses are all normalized to $100 \%$, the within sample variation is considerably larger than variation because of either of these two effects; we therefore consider all analyses in determining relative compositional variability between samples. Contamination of analyses by the surrounding matrix was monitored by measuring $\mathrm{Si}$ content, and any analysis with $>0.5 \quad$ wt $\% \quad \mathrm{SiO}_{2}$ was discarded. 
[21] To characterize oxide compositional variation among samples, we assumed spinel structure for all analyses, and calculated spinel end-members in the following manner:

[22] 1. All Ti was assigned to ulvöspinel $\left(\mathrm{Fe}_{2} \mathrm{TiO}_{4}\right)$.

[23] 2. All Mn (typically $<0.5 \mathrm{wt} \% \mathrm{MnO}$ ) was assigned to jacobsite $\left(\mathrm{MnFe}_{2} \mathrm{O}_{4}\right)$.

[24] 3. $\mathrm{Al}$ and $\mathrm{Mg}$ are assigned first to spinel $\left(\mathrm{MgAl}_{2} \mathrm{O}_{4}\right)$, then excess $\mathrm{Al}$ was assigned to hercynite $\left(\mathrm{FeAl}_{2} \mathrm{O}_{4}\right)$ or excess $\mathrm{Mg}$ was assigned to magnesioferrite $\left(\mathrm{MgFe}_{2} \mathrm{O}_{4}\right)$, then to magnesiochromite $\left(\mathrm{MgCr}_{2} \mathrm{O}_{4}\right)$ if all $\mathrm{Fe}$ was depleted.

[25] 4. The remaining $\mathrm{Cr}$ was assigned to chromite $\left(\mathrm{FeCr}_{2} \mathrm{O}_{4}\right)$.

[26] 5. The remaining $\mathrm{Fe}$ was assigned to magnetite $\left(\mathrm{Fe}_{3} \mathrm{O}_{4}\right)$.

[27] While this is a somewhat complex and nonunique solution, fewer end-members could not accommodate the often large amounts of $\mathrm{Mg}, \mathrm{Al}$, and $\mathrm{Cr}$.

[28] The area fractions of select phases were measured by thresholding the characteristic range of gray-scale values in backscatter electron images using ImageJ freeware (http:// rsb.info.nih.gov/ij/). For materials lacking textural fabric, the volume fraction of a given phase is equivalent to its area fraction in a 2-D slice [Hilliard, 1968].

\subsection{Rock Magnetic Analyses}

[29] Rock magnetic measurements were designed to place constraints on the grain size and composition of the magnetic phases present, as well as to test the remanencebearing capacity of the samples. Two sample splits were used for magnetic analyses. The first was used to measure saturation magnetization $\left(\mathrm{M}_{\mathrm{s}}\right)$ as a function of temperature from $50^{\circ} \mathrm{C}$ to $600^{\circ} \mathrm{C}$ in flowing $\mathrm{He}$ gas in an attempt to estimate Curie temperature $\left(\mathrm{T}_{\mathrm{c}}\right)$. A more complete battery of tests was carried out on the second split. Acquisition of anhysteretic remanent magnetization (ARM) was measured for all samples in a $100 \mathrm{mT}$ peak alternating field (AF) and a maximum $200 \mu \mathrm{T}$ DC bias field; this was followed by $\mathrm{AF}$ demagnetization of the ARM. Magnetization (M) versus applied field $(\mathrm{H})$ data were acquired on a subset of samples in order to determine hysteresis behavior of the samples for temperatures between $10 \mathrm{~K}$ and $300 \mathrm{~K}$. Field cooled - zero field cooled (FC-ZFC) experiments were carried out in part to constrain magnetic mineralogy: a $2.5 \mathrm{~T}$ saturation isothermal remanent magnetization (SIRM) was applied at $20 \mathrm{~K}$ and then measured while warming to $300 \mathrm{~K}$ following cooling in zero field and in a $2.5 \mathrm{~T}$ field. Additionally, on some samples a room temperature $(300 \mathrm{~K})$ SIRM was measured on cooling to $20 \mathrm{~K}$ and on warming back to room temperature. Susceptibility as a function of temperature $(20-300 \mathrm{~K})$ and frequency was also measured on many samples. Finally, samples were given a thermal remanence (TRM) at $550^{\circ} \mathrm{C}$ (chosen on the basis of $\mathrm{T}_{\mathrm{c}}$ ) in a $49 \mu \mathrm{T}$ field in $\mathrm{Ar}$ atmosphere. The TRM was measured and then progressively removed in $50^{\circ} \mathrm{C}$ steps between 100 and $550^{\circ} \mathrm{C}$. To monitor alteration, low-field susceptibility was measured following each heating treatment, and a second TRM at $49 \mu \mathrm{T}$ was given following the complete thermal demagnetization. Finally, TRMs were additionally imparted in $35 \mu \mathrm{T}$ and $80 \mu \mathrm{T}$ fields. All room temperature remanence measurements (ARM, TRM) were made in the paleomagnetic laboratory at University of Hawaii on a $2 \mathrm{G}$ cryogenic rock magnetometer. The remainder of the measurements was made at the Institute for Rock Magnetism at the University of Minnesota.

\section{Results}

[30] Where used, the buffer assemblage indicators showed no evidence for significant departure from either the IW or QFM buffer. In the more slowly cooled QFM samples, the assemblage was dominated by quartz and magnetite; although small amounts of fayalite could be found, it was typically armored by quartz grains, suggesting that the oxygen fugacity may have become somewhat more oxidizing than QFM. However, one experiment (T-type, $5.7^{\circ} \mathrm{C} \mathrm{h}^{-1}$ ) was repeated under flowing gases while monitoring $f \mathrm{O}_{2}$, and oxide compositions as measured by EMP were entirely consistent with those in the sample cooled in vacuum with the buffer assemblage.

\subsection{Petrographic and Compositional Analyses}

[31] Many of the charges are texturally heterogeneous on the millimeter scale, with spatial gradients in crystallinity, crystal size and morphology, and to a lesser extent, mineralogy. These variations are consistent with heterogeneous nucleation and diffusion controlled growth occurring during rapid cooling. Portions of material from throughout the charge were included in all thin sections and textural characterizations.

[32] The dominant phase in all experiments, regardless of bulk composition, cooling rate or $\mathrm{fO}_{2}$, is Ca-rich pyroxene (Figures 1 and 2). It occurs in a spectacular range of morphologies, ranging from feathery dendrites (e.g., Figures 1f, $1 \mathrm{~g}$, and $2 \mathrm{~g}$ ) to zoned, faceted laths (Figures 2c and 2d); in T-type samples it is frequently intimately intergrown with plagioclase (Figures $2 \mathrm{f}$ and $2 \mathrm{~h}$ ), a phase not observed in the M-type samples. Olivine (Figures 1a, $1 \mathrm{c}$, and 1d) is present in the M-type samples (most prevalent at IW), while only two T-type samples (IW; 18.7 and $5.7^{\circ} \mathrm{C} \mathrm{h}^{-1}$ ) have olivine (not shown). The T-type samples were on average finer grained and more crystalline than the M-type samples. Observations and trends in mineral abundance and texture with respect to $\mathrm{fO}_{2}$ and cooling rate are detailed below.

\subsubsection{Effects of Cooling Rate and $\mathrm{fO}_{2}$ on Silicate} Minerals

[33] Predictably, the result of decreasing cooling rate on both $\mathrm{M}$ - and T-type samples is to coarsen and mature the morphologies of silicate (and oxide) mineral phases. At $231^{\circ} \mathrm{C} \mathrm{h}^{-1}$, the morphologies of pyroxene and olivine formed at all $\mathrm{fO}_{2}$ values are dendritic, with large specific surface areas and low number densities suggesting that the dominant crystallization mechanism is diffusion-limited crystal growth. Plagioclase and $\mathrm{Ca}$ pyroxene in the holocrystalline T-type samples formed during rapid cooling $\left(231^{\circ} \mathrm{C} \mathrm{h}^{-1}\right)$ resemble fine-scale eutectic intergrowths (similar to texture shown in Figure 1e). Compact and faceted crystals, which presumably formed by interface-limited crystal growth [Kirkpatrick, 1981], occur only in slowcooled experiments (e.g., compare Figures $2 \mathrm{a}$ and $2 \mathrm{~d}$ ).

[34] Of the two samples that followed an exponentially varying temperature-time path, the M-type sample has pyroxene morphologies most similar to those of the more rapidly cooled $\left(\geq 72.4^{\circ} \mathrm{C} \mathrm{h}^{-1}\right)$ samples (Figure $2 \mathrm{e}$ ). The T-type sample is extremely heterogeneous; portions of the 

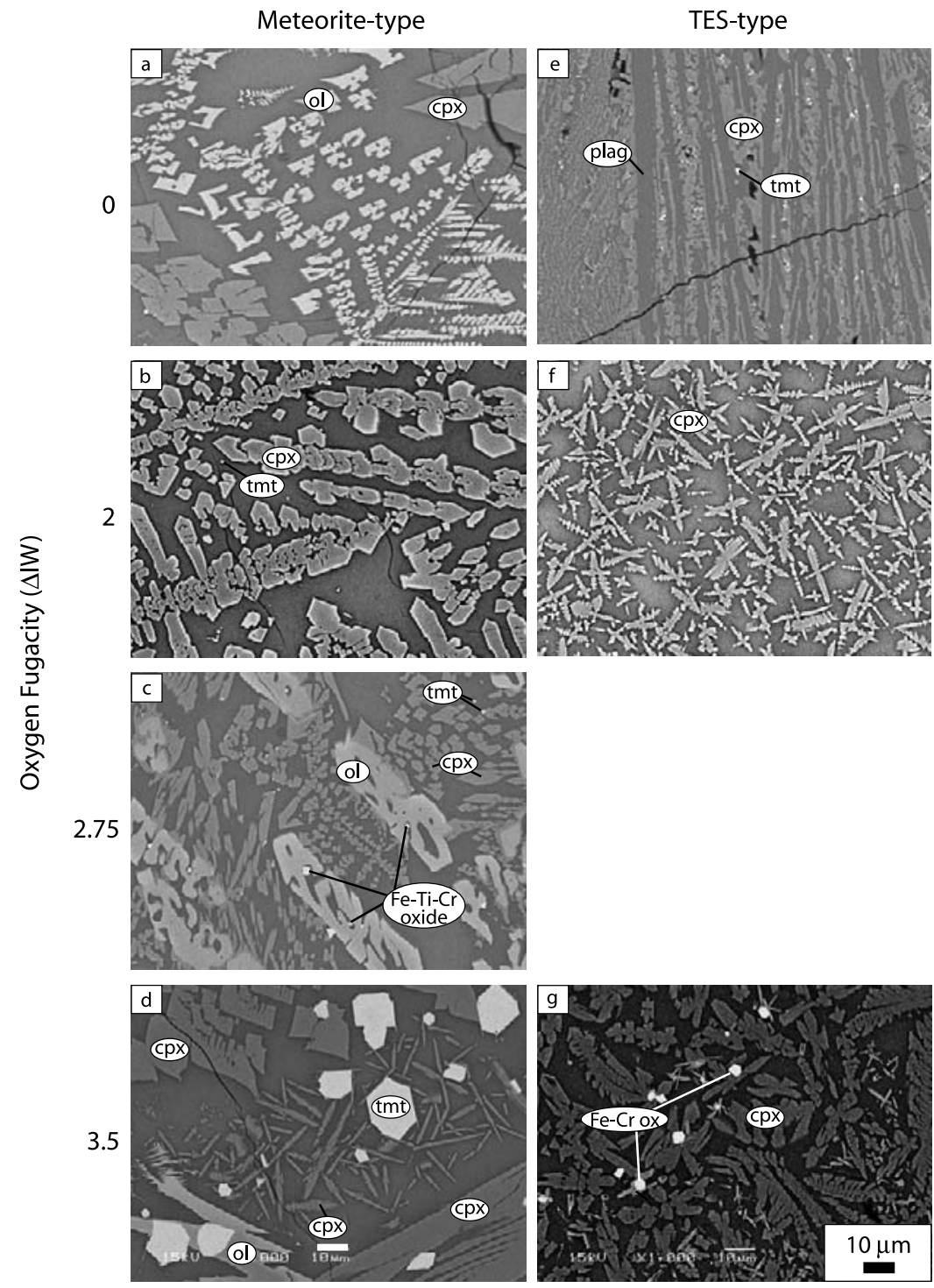

Figure 1. (a-g) Electron backscatter images of samples cooled at $72 \mathrm{~K} \mathrm{~h}^{-1}$ at indicated $f \mathrm{O}_{2}$. There is a general (but not absolute) trend toward larger and more abundant oxides at higher $f_{2}$. Here cpx, clinopyroxene; ol, olivine; plag, plagioclase; tmt, titanomagnetite; $\mathrm{Fe}(-\mathrm{Ti})-\mathrm{Cr}$ ox, iron(-titanium)chromium oxide. All oxides also contain some $\mathrm{Mg}+\mathrm{Al}$. Scale bar shown in Figure 1g applies to all other images.

sample are wholly glass, while other portions contain feathery or dendritic pyroxene, and some areas contain more faceted pyroxene (Figure $2 \mathrm{j}$ ).

[35] The effects of varying $f \mathrm{O}_{2}$ on M-type silicates are broadly similar at all cooling rates, chiefly controlling olivine abundance and morphology. The olivine correlation is weak at the fastest cooling rate $\left(231^{\circ} \mathrm{C} \mathrm{h}^{-1}\right)$, while at $72^{\circ} \mathrm{C} \mathrm{h}^{-1}$, an increase in $f \mathrm{O}_{2}$ from IW to QFM is accompanied by maturation of olivine morphology from skeletal toward faceted forms at essentially constant volumetric abundance. At slower cooling rates $\left(18.7\right.$ and $\left.5.7^{\circ} \mathrm{C} \mathrm{h}^{-1}\right)$, increasing $f \mathrm{O}_{2}$ is associated with decreased olivine content (from 15 and 8 vol.\%, respectively, at IW, to 0 vol.\% at QFM).

[36] In contrast, the effect of increasing $f \mathrm{O}_{2}$ is incoherent with respect to silicate mineralogy and morphology in T-type experiments. With slow cooling $\left(18.7\right.$ and $\left.5.7^{\circ} \mathrm{C} \mathrm{h}^{-1}\right)$, increasing $f \mathrm{O}_{2}$ is associated with declining olivine abundance (as observed in the M-type runs) as well as dramatically increasing plagioclase abundance (from 0 to $>30$ vol.\%). However, with fast cooling $\left(231\right.$ and $72.4^{\circ} \mathrm{C}$ $\mathrm{h}^{-1}$ ), olivine content is unchanged and plagioclase is either unchanged (at $\sim 45$ vol.\%) or completely absent (i.e., 0 vol.\%) with increasing $f \mathrm{O}_{2}$.

\subsubsection{Effects of Cooling Rate and $\mathrm{fO}_{2}$ on Oxide Mineralogy}

[37] Similar to the silicate phases, the effect of decreasing cooling rate at QFM in M-type oxides is to evolve from cruciform and skeletal oxides (Figure 2a, 2b, and 2c) to more equant and faceted grains (Figure 2d). Additionally, oxide grain size increases, from maximum grain diameters of $\sim 8 \mu \mathrm{m}$ at $231^{\circ} \mathrm{C} \mathrm{h}^{-1}$ to $\sim 40 \mu \mathrm{m}$ at $5.7^{\circ} \mathrm{C} \mathrm{h}^{-1}$. The variable cooling rate sample has a set of faceted grains with maximum diameters approaching that of the most slowly 


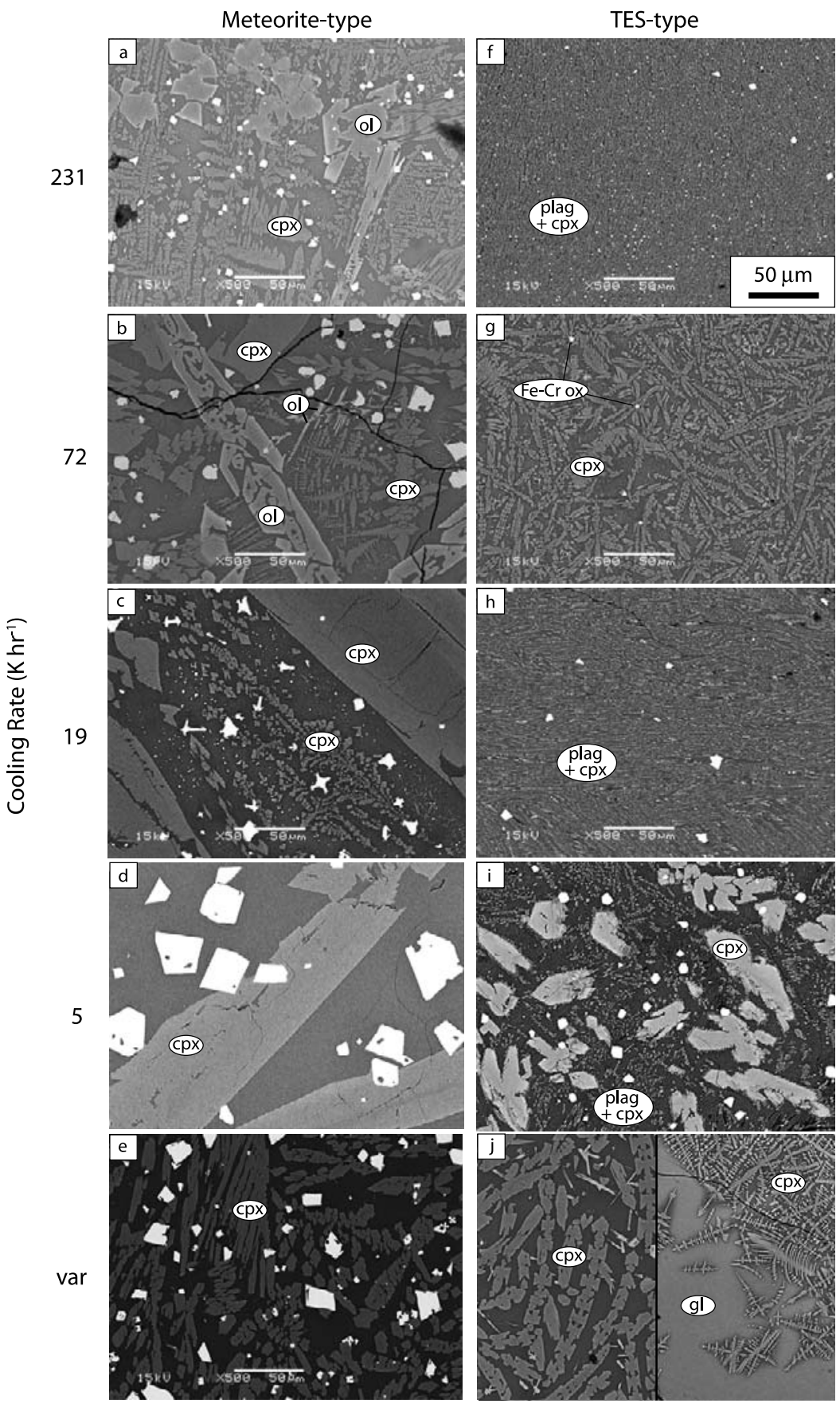

Figure 2. $(a-j)$ Electron backscatter images of samples cooled under QFM conditions at indicated cooling rates. Here "var" indicates exponentially varying cooling path. Scale bar is $50 \mu \mathrm{m}$. There is a general (but not absolute) trend toward larger grain size at slower cooling rates, most prominent in the M-type samples. Oxides appear as the highly reflective (bright) phase in each image. Figure $2 b$ also contains numerous skeletal and cruciform oxides. The fine-grained groundmass of Figures $2 \mathrm{f}, 2 \mathrm{~h}$, and $2 \mathrm{i}$ appears to be an intergrowth of plagioclase and clinopyroxene with interstitial oxides. Here gl, glass. Scale bar shown in Figure $2 \mathrm{f}$ applies to all other images.

cooled sample. However, this sample also has a population of smaller, cruciform grains that are not present in the most slowly cooled sample; most of these cruciform oxides are observed decorating pyroxene grain boundaries (Figure 2e).

[38] Increasing $f_{2}$ in M-type samples from IW to QFM at all cooling rates causes oxide abundance to increase. At $231^{\circ} \mathrm{C} \mathrm{h}^{-1}$, the increase is 0 to 4 vol.\%; at $72^{\circ} \mathrm{C} \mathrm{h}^{-1}, 0$ to
3 vol.\%; at $18.7^{\circ} \mathrm{C} \mathrm{h}^{-1}, 1$ to 4 vol.\%; and at $5.7^{\circ} \mathrm{C} \mathrm{h}^{-1}, 0$ to 8 vol.\%. In the more reduced samples, submicron oxides (when present) frequently appear either as decorations or as irregular rims on edges of pyroxene crystals. Two of the intermediate $f \mathrm{O}_{2}$ samples (IW $+2,18.7^{\circ} \mathrm{C} \mathrm{h}^{-1}$; IW +2.75 , $\left.72.4^{\circ} \mathrm{C} \mathrm{h}^{-1}\right)$ contain equant $(\sim 1-2 \mu \mathrm{m}$ diameter $)$, Cr-rich oxides within olivine hoppers (Figure 1c). Many samples 
additionally contain clusters of submicron, Cr-rich oxides, most prevalent in runs cooled under oxidizing conditions.

[39] In contrast to the M-type samples, which display clear trends with cooling rate and $\mathrm{fO}_{2}$, the T-type oxides show more complex behavior. At all $f_{2}$ and cooling rates, highly crystalline samples consistently contain small proportions of irregularly faceted submicron interstitial oxides (Figures 1e, 2f, 2h, and 2i), while samples less than $\sim 90$ vol.\% crystalline lack these interstitial oxides (Figures $1 \mathrm{f}, 1 \mathrm{~g}, 2 \mathrm{~g}$, and $2 \mathrm{j}$ ). At QFM, the samples additionally contain small amounts $(\leq 7$ vol.\%) of larger $(5-8 \mu \mathrm{m}$ diameter), compact and faceted oxide crystals, which are entirely lacking at more reducing conditions. The exception to this rule is the variable cooling rate sample (Figure $2 \mathrm{j}$ ), which shows a very low degree of crystallinity and maximum grain diameters of $\sim 0.5 \mu \mathrm{m}$. The clusters of $\mathrm{Cr}$-rich oxides observed in M-type samples are also present in $\mathrm{T}$ type samples, again more frequently under oxidizing conditions.

3.1.3. Comparison of M-Type and T-Type Mineralogy

[40] One important difference between the M-type and T-type experiments is the degree of crystallinity, which is consistently lower in the M-type samples. The largest difference is between experiments performed during slow cooling at QFM: the T-type sample is holocrystalline (100 vol.\% crystals (Figure 2i)), while the M-type sample contains only $\sim 50$ vol. $\%$ crystals (Figure $2 \mathrm{~d}$ ). Moreover, none of the M-type samples is more than 60 vol.\% crystalline. The difference is smaller (but not consistently so) at reducing conditions and more rapid cooling rates. This difference in crystallinity relates to two other observations: (1) oxides are equally abundant $(\sim 8$ vol.\%) in slow-cooled M-type and T-type runs at QFM (although this is not reflected in Figure 1), despite the M-type material having double the normative magnetite content (Table 1), and (2) samples that reached high crystallinities $(>80$ vol.\%) are invariably plagioclase-rich. Pertinent to both points, textures in the holocrystalline T-type runs (Figures $2 \mathrm{~h}$ and $2 \mathrm{i}$ ) suggest that extensive silicate crystallization in these experiments caused interstitial oxide crystallization relatively late in the cooling history. Despite its greater Fe content and thus greater capacity for oxide formation, the M-type material may contain lower-than-expected oxide contents because of comparatively sluggish silicate crystallization (Figures $2 \mathrm{c}$ and $2 \mathrm{~d}$ ) in this composition.

\subsubsection{Oxide Compositions}

[41] Quantitative compositional information by electron microprobe analysis (EMP) was only possible on grains $>1 \mu \mathrm{m}$. This precluded analyses on most samples formed at $f \mathrm{O}_{2}$ below the QFM buffer, as well as smaller grains in QFM samples. These smallest grains probably differ in composition from the larger crystals, insofar as size is correlated with the timing of nucleation with respect to cooling and therefore melt composition. With these caveats in mind, we report (Data Set S1) EMP analyses for all of the samples cooled at QFM (with the exception of the variable cooling rate T-type sample). ${ }^{1}$ Results of the spinel end-member calculations are shown in Figure 3.

\footnotetext{
${ }^{1}$ Auxiliary materials are available at ftp://ftp.agu.org/apend/je/ 2009je003378.
}

[42] To a large degree, the compositional trends in the experimentally grown oxides are consistent with expectation based on compositional differences between the M-type and T-type starting materials. For example, the oxides in Al-poor M-type run products have considerably less Al than the oxides in Al-rich T-type material. For crystals with nominal $\mathrm{Cr}$ content $(\sim 0.02$ atoms per formula unit), the M-type material crystallizes oxides with Al content of $\sim 0.14$ atoms per formula unit (apfu) compared to $\sim 0.45$ for the T-type starting material. Both starting materials produce oxides with a wide variety of chromite contents ( 0 to 1.0 apfu $\mathrm{Cr}$ ), tending to decrease as crystallization progresses, as ascertained from zoned crystals ( $\mathrm{Cr}$ content decreases from core to rim). Such $\mathrm{Cr}$ zoning in spinels is frequently observed in nature [e.g., Haggerty, 1991; de Wall et al., 2004].

[43] The slowest-cooled and variable cooling rate M-type samples are the only charges to exhibit compositionally homogeneous oxides. These faceted, coarse-grained crystals cluster near $M t_{75} U s p_{15} Z_{10}$ (where $\mathrm{Mt}_{\mathrm{xx}}$ is mole fraction of magnetite, $\mathrm{Usp}_{\mathrm{xx}}$ is ülvospinel, and $Z_{\mathrm{xx}}$ represents the summed mole fractions of spinel, chromite, magnesioferrite, magnesiochromite, and jacobsite compositional end-members) regardless of the size of the crystal analyzed, or placement of the focused electron beam with respect to the crystal core (Figure 3a). These crystals have roughly equal amounts of $\mathrm{Ti}, \mathrm{Mg}$, and $\mathrm{Al}$ and are relatively low in Cr (Figure 3b).

[44] M-type samples cooled at moderate rates exhibit a population composition near the slow-cooled cluster (with a slightly higher ülvospinel content) as well as sparse crystals that are much richer in nontitanomagnetite components (ranging up to $M t_{20} U s p_{10} Z_{70}$ ). The molar proportions of $\mathrm{Mg}$ end-members are reduced in most analyses compared to those in the slow-cooled samples, and much of the scatter in the data can be explained by varying $\mathrm{Cr}$ concentration. The most rapidly cooled $\mathrm{M}$-type oxides span a continuous range between $M t_{75} U s p_{15} Z_{10}$ and $M t_{20} U s p_{10} Z_{70}$, with no significant gaps in the spectrum. The spread in the data is almost entirely explained by variations in the $\mathrm{Cr}$ content (from 0.00 to $0.45 \mathrm{~mol}$ fraction chromite), and to a lesser extent, $\mathrm{Mg}$ and $\mathrm{Al}$ end-member components.

[45] In contrast to the M-type experiments, the slowest cooled T-type run at QFM contains a wide variety of oxide compositions. Resembling the fastest-cooled M-type run, the crystals analyzed in this sample exhibit a broad, continuous array of nontitanomagnetite contents from $M t_{50} U s p_{15} Z_{35}$ and $M t_{20} U s p_{5} Z_{75}$. Similar to the M-type run, most of the spread in the data can be explained by magnetite and ülvospinel components being replaced by a chromite component, and to a lesser extent by incorporation of $\mathrm{Mg}$ and $\mathrm{Al}$ end-member components. The samples cooled at the intermediate and fastest rates contain compositionally discrete crystals (rather than a continuum), with grains clustering near $M t_{7} U s p_{3} Z_{90}$ and $M t_{28} U s p_{33} Z_{39}$. These compositional differences have no obvious correlation with crystal size or morphology.

[46] Scarcity of crystals coarse enough for quantitative analysis suggests that the compositions plotted in Figure 3 may not accurately reflect the complete range and distribution of compositions in these samples. However, uniformity of the compositional trends (including the common Mt-Usp 


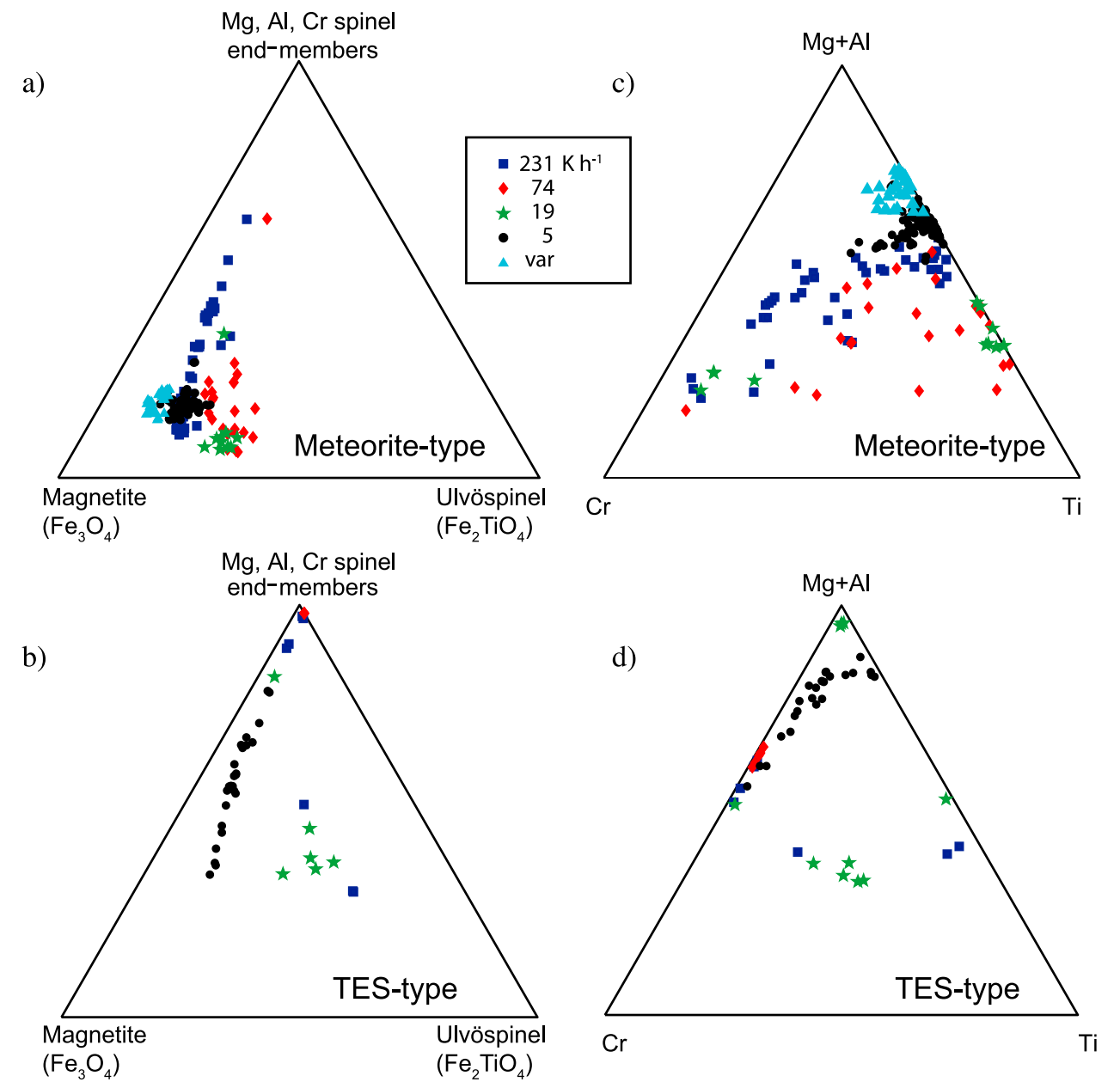

Figure 3. Microprobe analyses (QFM samples) assuming three cations per four oxygens (spinel structure). Oxide grains analyzed are typically $>1 \mu \mathrm{m}$ in diameter. Symbols represent single analyses, and legend shows cooling rate in $\mathrm{K} \mathrm{h}^{-1}$. Within-sample linear trends between end-members typically represent within-grain zoning. ( $\mathrm{a}$ and $\mathrm{b}$ ) Ternary plots with results of spinel end-member calculations. $\mathrm{Mg}, \mathrm{Al}$, and $\mathrm{Cr}$ end-members are predominantly spinel, chromite, magnesioferrite, and magnesiochromite (see text). (c and d) Ternary plots showing relative amounts of $\mathrm{Ti}, \mathrm{Cr}$, and $\mathrm{Mg}+\mathrm{Al}$ on a cation basis.

ratio among Usp-poor crystals and clustering of Usp-rich compositions) suggests that a similar liquid line of descent was traversed by all samples in the set, albeit to varying extents depending upon cooling rate.

\subsection{Magnetic Results}

\subsection{1. $M_{s}$ Versus $T$ (Curie Temperature Estimates)}

[47] Curie temperature $\left(T_{c}\right)$ was determined from the $M_{s}$ versus $\mathrm{T}$ measurements (by the method of two intersecting tangents) on all meteorite-type QFM samples, and two of five TES-type QFM samples. In other samples, the paramagnetic signal dominated the measurements. In the M-type samples, $\mathrm{T}_{\mathrm{c}}$ ranges from $340^{\circ} \mathrm{C}$ to $480^{\circ} \mathrm{C}$, consistent with cation-substituted magnetite. There is a general agreement between the EMP data and the $T_{c}$ estimates in that samples with lower average measured $\mathrm{Fe}$ content have lower $\mathrm{T}_{\mathrm{c}}$ estimates. Of the T-type samples for which data are available, the $T_{c}$ estimates provide evidence for a population of oxides more Fe-rich than those measured via EMP. One $\left(72.4^{\circ} \mathrm{C} \mathrm{h}^{-1}\right)$ has two distinct Curie temperatures $\left(240^{\circ} \mathrm{C}\right.$ and $443^{\circ} \mathrm{C}$ ), in spite of the fact that the EMP analyses cluster near the $\mathrm{Mg}, \mathrm{Al}$, and $\mathrm{Cr}$ end-members on the ternary plot (Figure 3). We interpret these to represent a chromerich $\left(240^{\circ} \mathrm{C}\right)$ and a chrome-poor $\left(443^{\circ} \mathrm{C}\right)$ phase, similar to those observed in natural, terrestrial chromite-bearing rocks [Radhakrishna Murthy and Krishnamacharyulu, 1994; Kumar and Bhalla, 1984]. The slowly cooled $\left(5.7^{\circ} \mathrm{C} \mathrm{h}^{-1}\right)$ TES-type sample has a Curie temperature $\left(484^{\circ} \mathrm{C}\right)$ more consistent with the most magnetite-like of the EMP analyses, suggesting that the bulk of the unmeasured (smaller) crystals are more Fe-rich than the larger, measured crystals.

\subsubsection{Hysteresis Data}

[48] Room temperature hysteresis measurements allow us to place constraints on the average magnetic grain size and domain state of the samples, including grains smaller than the resolution of the SEM. Within a given composition, $\mathrm{fO}_{2}$ exerts the dominant control on grain size, while cooling rate plays a secondary role (Figure 4). Samples cooled under more oxidizing conditions and at slower cooling rates display more multidomain-like behavior. We note that this holds true even for T-type samples, which showed no obvious trends in oxide size with cooling rate in the EBS 


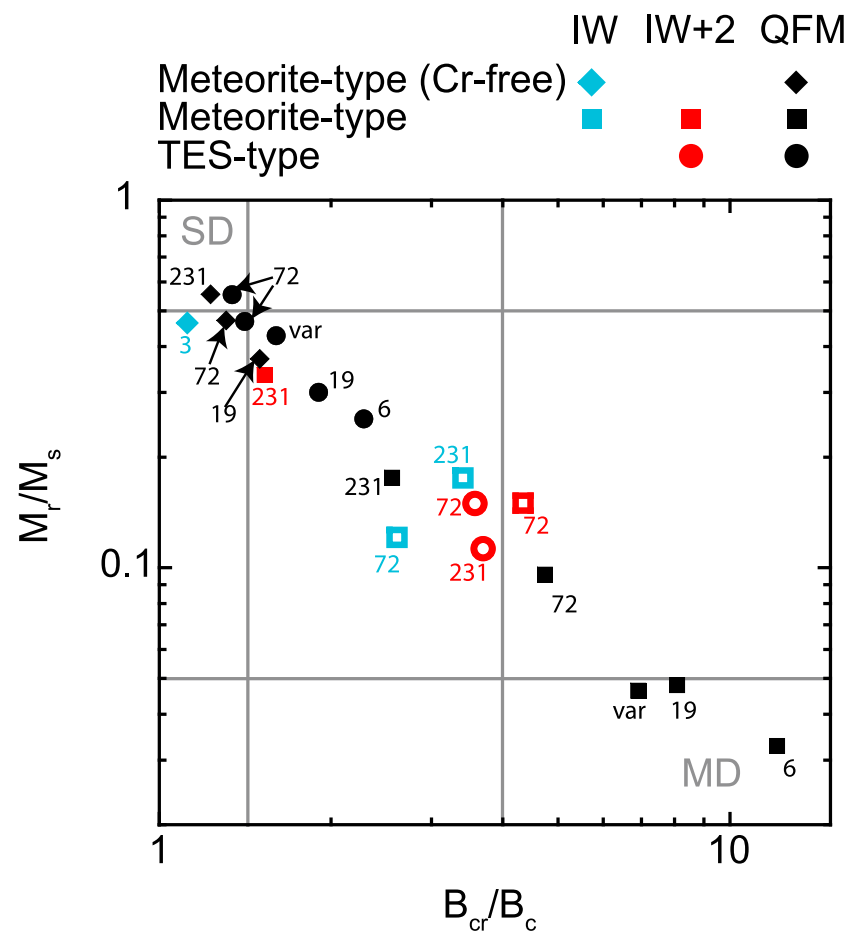

Figure 4. Room temperature hysteresis data. Cooling rate shown in $\mathrm{K} \mathrm{h}^{-1}$ next to data points. Data from Cr-free samples from Brachfeld and Hammer [2006]. Open symbols likely contain a significant superparamagnetic contribution. Plot subdivisions for magnetite shown for reference.

imagery. Some of the more reduced samples that plot along the SD-MD mixing trend show no visible oxides in the electron backscatter images or only show tiny, submicron oxides. These data are plotted as open symbols in Figure 4, and we suggest they represent mixtures of SD and superparamagnetic (SP) grain size populations, rather than SDMD. Low-temperature remanence (e.g., Figures $5 \mathrm{~g}$ and $5 \mathrm{~h}$ and section 3.2.3) and susceptibility (Figures $6 \mathrm{e}$ and $6 \mathrm{f}$ and section 3.2.4) data are also indicative of a significant SP population.

[49] As mentioned above, oxides in T-type samples visually appear smaller on average than in the M-type samples, and this distinction can also be seen in the hysteresis data. Interestingly, the data for the Cr-rich M-type samples are consistent with a much larger average magnetic grain size than the Cr-free samples of Brachfeld and Hammer [2006] (also shown in Figure 4). EBS imagery reveals that the maximum average grain size is indeed considerably larger in the Cr-rich samples. We attribute this to the presence of highly compatible $\mathrm{Cr}$, which may increase the temperature at which an oxide phase is stable, thus enabling oxides growth to a larger size.

[50] Hysteresis was also measured as a function of temperature for most of the QFM samples. More reduced samples were typically dominated by a paramagnetic signal, making calculation of hysteresis parameters difficult. All QFM samples, however, show a dramatic increase in coercivity below $\sim 100 \mathrm{~K}$ that peaks at $\sim 40-50 \mathrm{~K}$ for M-type samples and the most slowly cooled T-type sample, or continues to increase to the lowest measured temperature $(10 \mathrm{~K})$ for other T-type samples. This is likely related to a large increase in both magnetocrystalline anisotropy and magnetostriction in titanomagnetites at low temperatures [Schmidbauer and Readman, 1982; Moskowitz et al., 1998]. Saturation magnetization $\left(\mathrm{M}_{\mathrm{s}}\right)$ decreases with decreasing temperature in all but one (variable cooling rate) of the meteorite-type samples; we interpret this as incomplete saturation of the titanomagnetite resulting in an overestima-
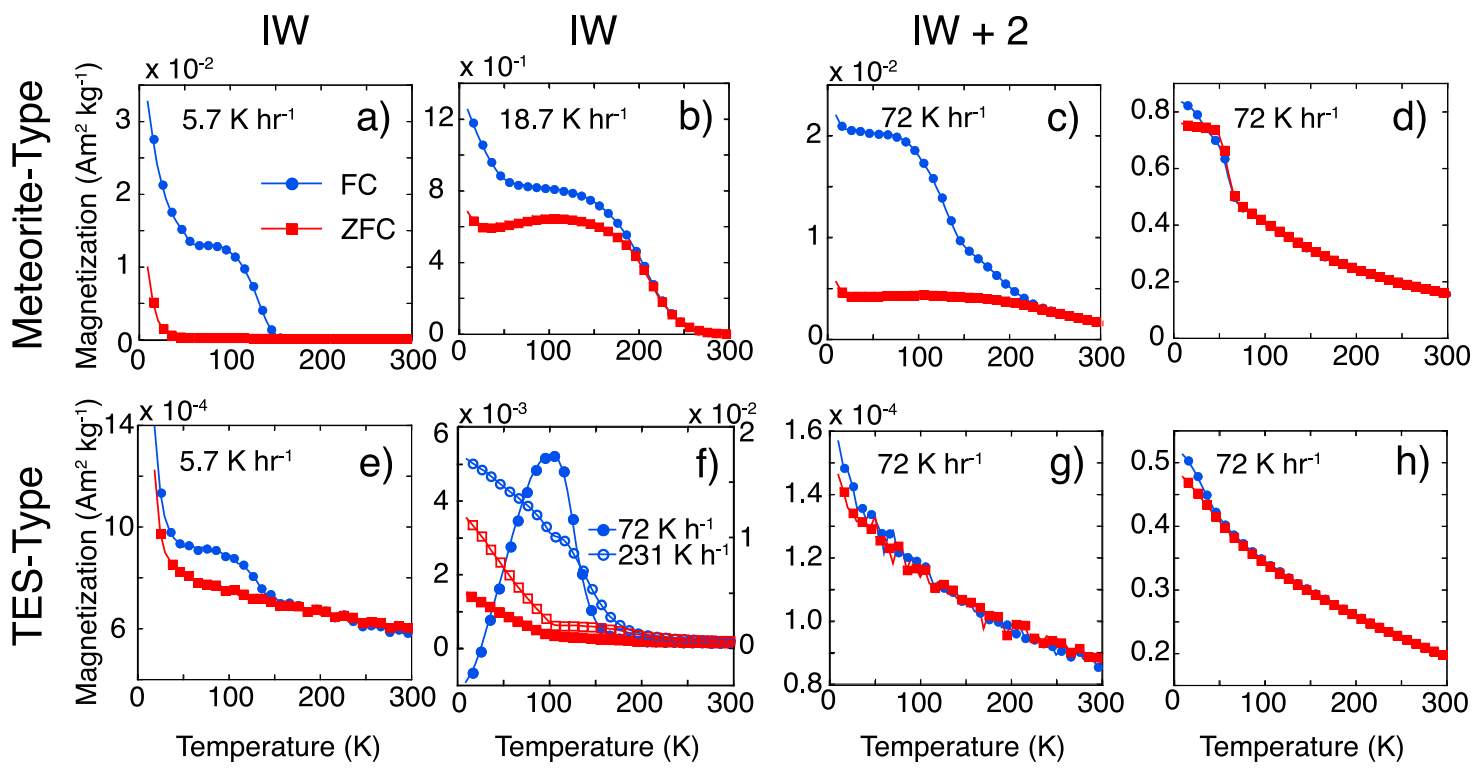

Figure 5. SIRM imparted at $10 \mathrm{~K}$ or $20 \mathrm{~K}$ and measured on warming after cooling in $2.5 \mathrm{~T}$ field (FC, blue circles) and in zero field (ZFC, red circles). Note varying order of magnitude on magnetization scales. For both compositions, the FC remanence is always greater than (or equal to) the $\mathrm{ZFC}$ remanence, even in the most slowly cooled samples. This is in contrast to observations by Carter-Stiglitz et al. [2006], showing that the reverse is true for multidomain $\mathrm{Fe}_{3-\mathrm{x}} \mathrm{Ti}_{\mathrm{x}} \mathrm{O}_{4}$ with $\mathrm{x}$ up to at least 0.35 . 


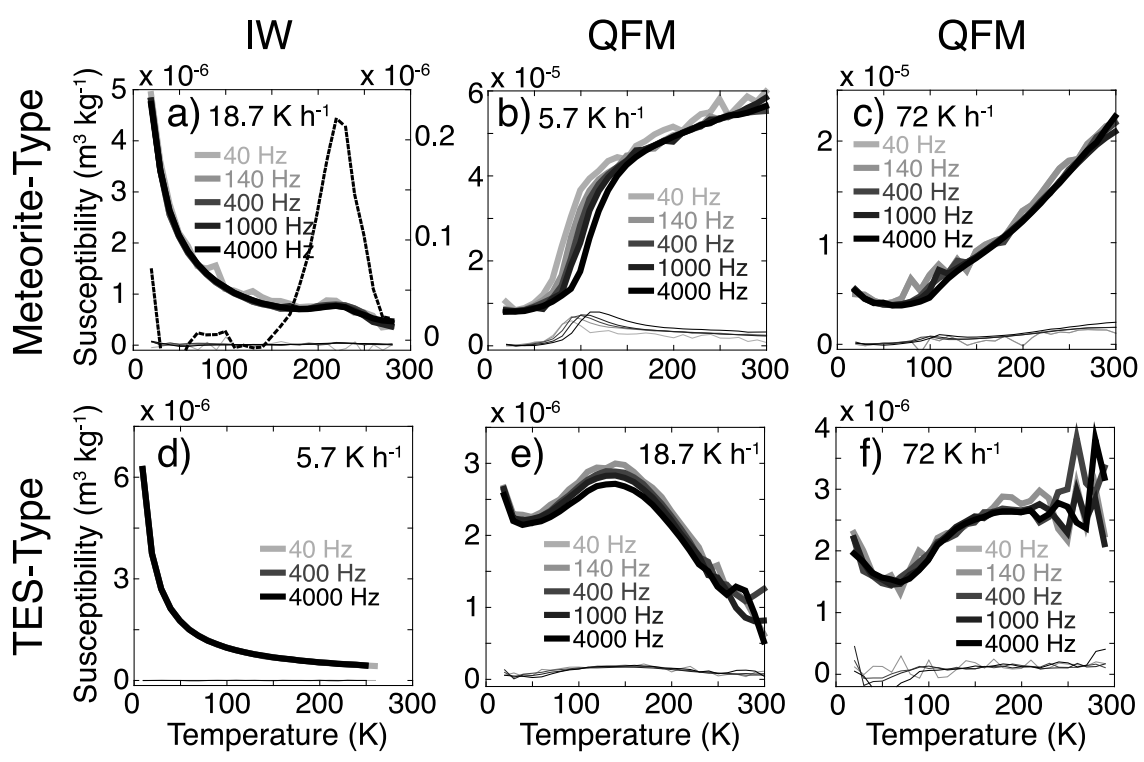

Figure 6. (a-f) Frequency and temperature dependence of susceptibility. In-phase (out-of-phase) data shown in thick (thin) lines. Dashed line in Figure 6a is $4000 \mathrm{~Hz}$ data with estimated paramagnetic signal removed; scale on right-hand axis. M-type QFM samples at 231 and $19 \mathrm{~K} \mathrm{~h}^{-1}$ (not shown) are similar to Figure 6c. T-type QFM samples at 231 and $5.7 \mathrm{~K} \mathrm{~h}^{-1}$ are similar to Figures $6 \mathrm{~d}$ and $6 \mathrm{c}$, respectively. All IW samples not shown are similar to Figure 6d.

tion of the paramagnetic component, and therefore an underestimate of $\mathrm{M}_{\mathrm{s}}$.

\subsubsection{Low-Temperature Remanence (FC-ZFC)}

[51] The low-temperature SIRM data for all QFM M-type samples are characterized by a large decrease in magnetization on warming at $\sim 50-60 \mathrm{~K}$ (Figure $5 \mathrm{~d}$ ), and the magnitude of the drop increases with decreasing cooling rate. The temperature of this transition $\left(\mathrm{T}_{\text {crit }}\right)$ is similar to that observed by Brachfeld and Hammer [2006] where it was interpreted as a magnetic isotropic point in low-Ti titanomagnetite [e.g., Moskowitz et al., 1998]. The cooling rate dependence may be related to grain size, and is similar to a grain size trend observed by Moskowitz et al. [1993] in synthetic SD magnetite. The pattern with respect to degree of cation substitution in the magnetite is consistent with that observed by Moskowitz et al. [1998]; samples determined to have more cation substitution on the basis of both EMP and Curie temperature analyses show little to no loss of remanence in the ZFC warming curve at temperatures below $\mathrm{T}_{\text {crit }}$. Samples with less cation substitution show a more rapid decay in remanence on warming below $\mathrm{T}_{\text {crit. }}$ The T-type samples display a similar, though much less abrupt, remanence drop at slightly lower temperatures (Figure $5 \mathrm{~h}$ ). This pattern could imply a lower degree of cation substitution, which is consistent with the available $T_{c}$ data; however, the transition may be somewhat obscured by the gradual unblocking of a considerable SP component (also observed in the IW + 2 T-type samples, Figure $5 \mathrm{~g}$ ).

[52] In contrast to the QFM samples, all IW samples (except the T-type samples cooled at 231 and $72^{\circ} \mathrm{C} \mathrm{h}^{-1}$ ) have a phase that rapidly unblocks between 10 and $60 \mathrm{~K}$ (Figures 5a, 5b, and 5e). This is consistent with high-Ti hemoilmenite, which carries a high remanence in the spin glass phase at temperatures $<\sim 50 \mathrm{~K}$ [Burton et al., 2008]. Additionally, all IW samples (except the M-type sample cooled at $18.7^{\circ} \mathrm{C} \mathrm{h}^{-1}$ ) have a phase that orders or blocks between $\sim 130 \mathrm{~K}$ and $\sim 150 \mathrm{~K}$ (Figures $5 \mathrm{a}, 5 \mathrm{e}$, and $5 \mathrm{f}$ ). The MELTS algorithm predicts both an ilmenite rich (90 mol \%) rhombohedral phase and a Ti-rich spinel phase. The observed blocking at $130-150 \mathrm{~K}$ could be consistent with a spinel phase that is rich in $\mathrm{Ti}$ and other non-Fe cations.

[53] At least two other phases appear to be present in some of the IW samples. The M-type, $18.7^{\circ} \mathrm{C} \mathrm{h}^{-1}$ sample (as well as the M-type, IW +2 sample) has a phase that blocks at $\sim 220 \mathrm{~K}$ (Figures $5 \mathrm{~b}$ and $5 \mathrm{c}$ ). A peak in the susceptibility data (below and Figure 6a) at the same temperature is interpreted as a Néel point, indicative of an antiferromagnetic spin structure. This could be a spinel of a slightly different composition. We note that Cr-rich oxides are observed in the EDS data for this sample, and $\mathrm{Fe}-\mathrm{Cr}$ spinels with ordering points in this temperature range would be antiferromagnetic [Robbins et al., 1971]. Again, it is likely that there are also other cations $(\mathrm{Mg}, \mathrm{Al})$ in the crystal structure, making a precise determination as to mineralogy difficult for all of these phases.

[54] Finally, the rapidly cooled $\left(231\right.$ and $\left.72^{\circ} \mathrm{C} \mathrm{h}^{-1}\right)$ T-type samples (Figure 5f) have a phase that orders below $100 \mathrm{~K}$. Interestingly, this phase appears to be antiferromagnetically coupled to the $\sim 150 \mathrm{~K}$ phase in the $72^{\circ} \mathrm{C} \mathrm{h}^{-1}$ sample (Figure 5f, solid circles), suggesting a two-phase intergrowth or another form of close coupling. Both of these samples (along with the M-type, IW, $231^{\circ} \mathrm{C} \mathrm{h}^{-1}$ sample) were suspended on $\mathrm{Pt}(-\mathrm{Fe})$ wire spirals during synthesis. Equivalent measurements carried out on a fragment of this wire from the $231^{\circ} \mathrm{C} \mathrm{h}^{-1}$ sample show some evidence for an ordering temperature at $\sim 100 \mathrm{~K}$. This phase may therefore result from contamination of the sample with the wire or an iron oxide coating on the wire. A wire fragment from the $72^{\circ} \mathrm{C} \mathrm{h}^{-1}$ sample showed no evidence for ordering temperatures between 10 and $300 \mathrm{~K}$, but did acquire a magnetization at $10 \mathrm{~K}$. 
[55] We note that the magnetic phases that are ordered below $130-150 \mathrm{~K}$ will not play a role in the magnetization of Mars' crust. The minimum surface temperature at Mars' poles is presently $150 \mathrm{~K}$, warm enough that the inferred phases, if present on Mars, would behave paramagnetically. Only phases that are magnetically ordered with a nonzero moment (ferrimagnetic, canted antiferromagnetic) at and above surface temperatures are relevant to crustal magnetization.

\subsubsection{Low-Temperature Susceptibility}

[56] M-type QFM samples display a frequency dependence in susceptibility between $\sim T_{\text {crit }}$ (above) and $\sim 120$ $140 \mathrm{~K}$, over which interval susceptibility increases sharply on warming (Figures $6 \mathrm{~b}$ and $6 \mathrm{c})$. The high- $\mathrm{T}_{\mathrm{c}}\left(\sim 470^{\circ} \mathrm{C}\right)$ samples display a relatively large increase in susceptibility at or above $T_{\text {crit }}$ (Figure 6b), while the lower- $T_{c}(\sim 330-$ $340^{\circ} \mathrm{C}$ ) samples show a smaller increase at $\mathrm{T}_{\text {crit }}$ (Figure 6c); these patterns are similar to variations with composition observed in titanomagnetite [Moskowitz et al., 1998; CarterStiglitz et al., 2006]. Only the most slowly cooled T-type sample shows a hint of a similar transition. Data from more rapidly cooled samples (Figures 6e and 6f) are dominated by a broad peak showing frequency dependence characteristic of a large SP fraction [Worm, 1998; Worm and Jackson, 1999], or by a paramagnetic signal $\left(231^{\circ} \mathrm{C} \mathrm{h}^{-1}\right.$, not shown).

[57] All IW samples are characterized only by a paramagnetic signal (e.g., Figure 6d), with two exceptions. The M-type, $18.7^{\circ} \mathrm{C} \mathrm{h}^{-1}$ sample (Figure 6a) has a peak at $\sim 220 \mathrm{~K}$, as mentioned in section 3.2.3. After removing the paramagnetic signal (by assuming it is similar to those in other M-type IW samples) the resulting curve (Figure 6a, dashed line) is reminiscent of an antiferromagnetic Néel point. Because this phase also carries a remanence (section 3.2.3), we assume it is canted or a defect moment.

[58] The second exception is the T-type $231^{\circ} \mathrm{C} \mathrm{h}^{-1}$ sample which shows evidence for a blocking temperature at $\sim 200 \mathrm{~K}$. Similar susceptibility behavior is observed a fragment of the $\mathrm{Pt}(-\mathrm{Fe})$ wire used for this sample, and as in the remanence-bearing phase that orders $<100 \mathrm{~K}$ (section 3.2.3), we interpret this as contamination from the wire.

\subsubsection{Thermal Remanence}

[59] The intensity of TRM acquired is most strongly influenced by $f_{2}$. In M-type samples, there is roughly linear relationship between $\log _{10} f \mathrm{O}_{2}$ and $\log _{10}$ TRM acquired in a $49 \mu \mathrm{T}$ field (Figure $7 \mathrm{a}$ ). We note that this trend likely cannot be extrapolated to higher $f \mathrm{O}_{2}$, as larger, MD grains are not as efficient in acquiring a remanence; this can be seen in the work by Brachfeld and Hammer [2006], where TRM shows no dependence on $f \mathrm{O}_{2}$ for $f \mathrm{O}_{2} \geq$ QFM. The relationship is somewhat more complicated in T-type samples (Figure 7b). At $f \mathrm{O}_{2} \leq \mathrm{IW}+2$ intensity is uniformly low (but above the noise level of the magnetometer). At QFM, remanence acquired varies over nearly 3 orders of magnitude, but the TRM of the most strongly magnetized samples is of the same order of magnitude as the M-type samples. Samples of both compositions that display no evidence for alteration with repeated heating show a linear relationship between applied field and acquired magnetization.

[60] Median destructive temperatures (MDT) derived from thermal demagnetization of the TRM (Figures 7c and $7 \mathrm{~d}$ ) may provide additional constraints on oxide com- position, although there is some evidence for sample alteration during the demagnetization. Weak-field susceptibility showed no consistent variation as the demagnetization progressed, but the duplicate TRM imparted after the complete demagnetization was considerably different for many samples. In general, QFM samples tended to show a slight reduction in acquired remanence, while more reduced samples showed an increase in remanence. The absolute magnitude of the change was a strong function of oxygen fugacity, with more reduced samples showing a greater degree of alteration, as might be expected since they are further from their "equilibrium" $f \mathrm{O}_{2}$. We assume, however, that the alteration was progressive, and that the initial TRM acquired is the least affected. We denote samples with a $>20 \%$ change in remanence with open symbols in Figures $7 \mathrm{c}$ and $7 \mathrm{~d}$. While the MDT of the more reduced samples especially must be treated with some skepticism, there are intriguing differences between the two bulk compositions. On average, with a decrease in $f \mathrm{O}_{2}$, the MDT of the M-type samples decreases, suggesting an increase in non-Fe cations, while that of the T-type samples increases, suggesting a phase closer to that of pure magnetite.

\subsubsection{Anhysteretic Remanence}

[61] ARM acquired at $100 \mathrm{mT} \mathrm{AF}$ in a $200 \mu \mathrm{T}$ bias field is of the same order of magnitude as the TRM acquired in a $49 \mu \mathrm{T}$ field, with no consistent offset in the positive or negative direction. The same trends in intensity with $f \mathrm{O}_{2}$ are also observed. ARM acquisition is linear with applied DC field. Trends in cooling rate and composition can be seen in the coercivity spectra of the samples as determined by stepwise AF demagnetization of the ARM. Median destructive fields (MDF (Table 2)) of the T-type samples are consistently higher than those of the M-type samples, consistent with the hysteresis data and the observed smaller grain size. Additionally, within each composition at QFM, there is a trend of generally increasing MDF with increasing cooling rate, again corresponding to smaller average magnetic grain size at faster cooling rates. A strong outlier is the T-type sample cooled at $72.4^{\circ} \mathrm{C} \mathrm{h}^{-1}$. Although one split of this sample is in line with the rest of the samples, a second split is considerably harder than all other measured samples, with an MDF of $\sim 58 \mathrm{mT}$. The sample retains $22 \%$ of its magnetization at $100 \mathrm{mT} \mathrm{AF}$. We note that the (few) EMP data available for this sample have the highest $\mathrm{Cr}$ content of any samples, and nonquantitative EDS data show that all analyzed grains contain significant $\mathrm{Cr}$. Elevated coercivity has been linked to a Cr-rich spinel in natural rocks [Kumar and Bhalla, 1984; Radhakrishna Murthy and Krishnamacharyulu, 1994], and that may be the case here. MDF is more difficult to calculate accurately at lower $f_{2}$ where the signal-to-noise ratio is considerably lower, and there are no obvious trends with cooling rate.

\section{Discussion}

[62] The overall goal of this study is to understand how variations in bulk melt composition, $f \mathrm{O}_{2}$, and cooling rate affect the resulting magnetic assemblage in a relatively rapidly cooled basalt. How do these factors control both the intensity of magnetization, as well as its stability with respect to temperature and time? Although the remanence carrying capacity of the samples is easy to measure, stability 

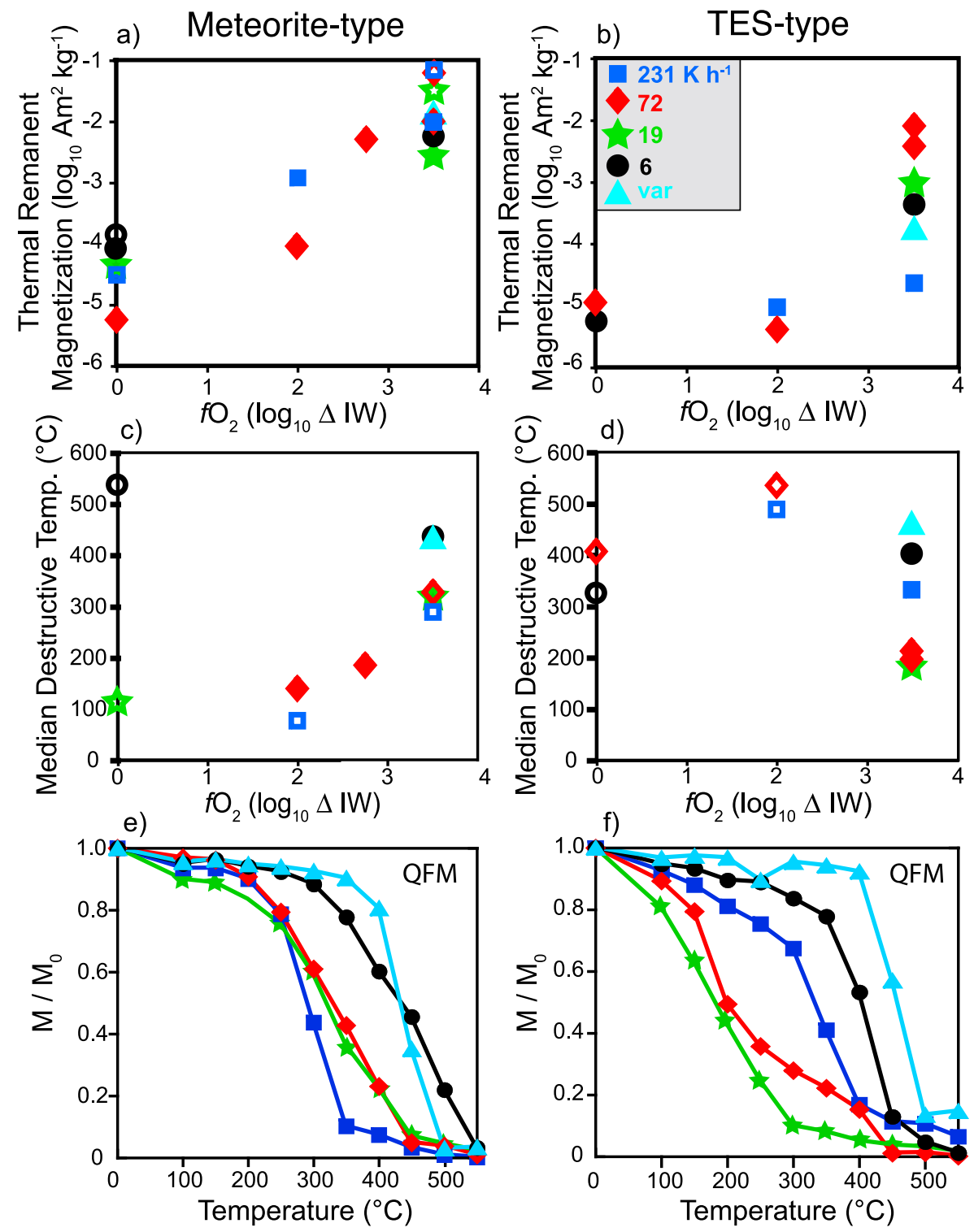

Figure 7. ( $a$ and $b$ ) Thermal remanent magnetization acquired in a $49 \mu \mathrm{T}$ field. (c and d) Median destructive temperature derived from thermal demagnetization of TRM in Figures 7a and 7b. (e and f) Complete thermal demagnetization curves for QFM samples only. Note that open symbols represent different things in Figure 7a and in Figures 7c and 7d. In Figure 7a open symbols are Cr-free samples from Brachfeld and Hammer [2006]; in Figures 7c and 7d open symbols indicate samples that show evidence for alteration at some point during the thermal demagnetization (see text).

with respect to temperature is largely related to composition, and stability through time is predominantly a function of oxide grain size. We will therefore briefly summarize our findings with respect to these two parameters before evaluating the role that our experimental variables play in controlling magnetic properties. We will also address how the resulting magnetic properties can be interpreted in terms of a potential contribution to the Mars magnetic source layer.

\subsection{Oxide Composition and Implications for Crystal Nucleation and Growth}

[63] M-type QFM samples have analytical (EMP) data broadly consistent with the magnetism-based characterization of composition. The most slowly cooled samples and variably cooled M-type samples vary little in EMP analyses (Figure 3), having typical compositions of $\mathrm{Fe}_{2.47} \mathrm{Ti}_{0.17}$ $\mathrm{Al}_{0.17} \mathrm{Mg}_{0.14} \mathrm{Cr}_{0.02} \mathrm{Mn}_{0.03} \mathrm{O}_{4}$ and $\mathrm{Fe}_{2.53} \mathrm{Ti}_{0.12} \mathrm{Al}_{0.15}$ $\mathrm{Mg}_{0.15} \mathrm{Cr}_{0.01} \mathrm{Mn}_{0.03} \mathrm{O}_{4}$, respectively. The Curie temperature $\left(\mathrm{T}_{\mathrm{c}}\right)$ of pure titanomagnetite with 2.5 apfu iron (i.e., $\mathrm{Fe}_{2.5} \mathrm{Ti}_{0.5} \mathrm{O}_{4}$ ) is $\sim 280^{\circ} \mathrm{C}$ [Dunlop and Özdemir, 1997]. However, the presence of other non-Fe cations can dramatically affect $\mathrm{T}_{\mathrm{c}}$. For example, an oxide with 2.5 apfu $\mathrm{Fe}$ in the magnetite $\left(\mathrm{Fe}_{3} \mathrm{O}_{4}\right)$ spinel $\left(\mathrm{MgAl}_{2} \mathrm{O}_{4}\right)$ solid solution has $\mathrm{T}_{\mathrm{c}} \sim 480^{\circ} \mathrm{C}$ [Harrison and Putnis, 1996], which is very close to our measured $\mathrm{T}_{\mathrm{c}}$ of $468^{\circ} \mathrm{C}$ and $477^{\circ} \mathrm{C}$ for these two samples. In general we find that our measured $\mathrm{T}_{\mathrm{c}}$ and $\mathrm{Fe}$ values are consistent with data from the magnetite-spinel system; measured $\mathrm{T}_{\mathrm{c}}$ (Table 2 ) in samples cooled between 
Table 2. Sample Experimental Conditions and Magnetic Properties

\begin{tabular}{|c|c|c|c|c|c|c|c|c|c|c|c|}
\hline Sample & $\begin{array}{c}\text { Desired } \\
f^{O_{2}} \\
\end{array}$ & $\begin{array}{l}\text { Cooling Rate } \\
\left(\operatorname{deg~} \mathrm{C} \mathrm{h}^{-1}\right)\end{array}$ & $\begin{array}{c}\text { Container } \\
\text { Material } \\
\end{array}$ & $\begin{array}{c}f \mathrm{O}_{2} \\
\text { Control }^{\mathrm{a}} \\
\end{array}$ & Batch $^{\text {b }}$ & $\begin{array}{c}\mathrm{T}_{\mathrm{c}}^{\mathrm{c}} \\
(\operatorname{deg} \mathrm{C}) \\
\end{array}$ & $\begin{array}{l}\text { MDT }^{\mathrm{d}} \\
(\operatorname{deg} \mathrm{C})\end{array}$ & $\begin{array}{r}\mathrm{MDF}^{\mathrm{e}} \\
(\mathrm{mT}) \\
\end{array}$ & $\begin{array}{c}\mathrm{M}_{\mathrm{rs}}{ }^{\mathrm{f}} \\
\left(\mathrm{Am}^{2} \mathrm{~kg}^{-1}\right) \\
\end{array}$ & $\begin{array}{c}\mathrm{ARM} \\
\left(\mathrm{Am}^{2} \mathrm{~kg}^{-1}\right)\end{array}$ & $\begin{array}{c}\text { TRM } \\
\left(\mathrm{Am}^{2} \mathrm{~kg}^{-1}\right) \\
\end{array}$ \\
\hline \multicolumn{12}{|c|}{ Meteorite Type } \\
\hline MAm-11 & QFM & 231 & capsule & $\mathrm{T}$ & 1 & 398 & 291 & 16.1 & $4.84 \mathrm{E}-01$ & $1.57 \mathrm{E}-02$ & $8.54 \mathrm{E}-03$ \\
\hline MAm-13 & QFM & 72.4 & capsule & $\mathrm{T}$ & 1 & 340 & 330 & 15.4 & $2.11 \mathrm{E}-01$ & $6.90 \mathrm{E}-03$ & $1.01 \mathrm{E}-02$ \\
\hline MAm-12 & QFM & 18.7 & capsule & $\mathrm{T}$ & 1 & 366 & 320 & 9.8 & $1.73 \mathrm{E}-01$ & $5.77 \mathrm{E}-03$ & $2.71 \mathrm{E}-03$ \\
\hline MAm-20 & QFM & 5.7 & capsule & $\mathrm{T}$ & 2 & 468 & 435 & 9.1 & $1.61 \mathrm{E}-01$ & 7.02E-03 & $5.80 \mathrm{E}-03$ \\
\hline MAm-17 & QFM & $\operatorname{var}^{\mathrm{g}}$ & capsule & $\mathrm{T}$ & 2 & 477 & 434 & 9.1 & $3.78 \mathrm{E}-01$ & $1.30 \mathrm{E}-02$ & $1.35 \mathrm{E}-02$ \\
\hline MAm-31 & $\mathrm{IW}+2.75$ & 72.4 & wire & $\mathrm{T}$ & 2 & & 186 & 35.1 & $5.81 \mathrm{E}-02$ & $3.64 \mathrm{E}-03$ & $5.10 \mathrm{E}-03$ \\
\hline MAm-19 & IW+2 & 231 & capsule & G & 2 & & 78 & 21.5 & $1.43 \mathrm{E}-02$ & $3.34 \mathrm{E}-03$ & $1.20 \mathrm{E}-03$ \\
\hline MAm-18 & IW+2 & 72.4 & capsule & G & 2 & & 139 & 23.4 & & $1.76 \mathrm{E}-04$ & $9.04 \mathrm{E}-05$ \\
\hline MAm-23 & IW & 231 & wire & G & 2 & & & & & 2.37E-05 & $4.36 \mathrm{E}-05$ \\
\hline MAm-29 & IW & 72.4 & capsule & $\mathrm{T}$ & 2 & & & 12.6 & $1.36 \mathrm{E}-03$ & $1.92 \mathrm{E}-05$ & $5.94 \mathrm{E}-06$ \\
\hline MAm-21 & IW & 18.7 & capsule & $\mathrm{T}$ & 2 & & 112 & 10.2 & & $6.73 \mathrm{E}-05$ & $4.98 \mathrm{E}-05$ \\
\hline \multicolumn{12}{|c|}{ TES Type } \\
\hline MB2-10 & QFM & 231 & capsule & $\mathrm{T}$ & 1 & & 333 & 41.9 & & $1.07 \mathrm{E}-05$ & 2.31E-05 \\
\hline MB2-09 & QFM & 72.4 & capsule & $\mathrm{T}$ & 1 & 443,240 & 215 & 24.5 & $2.10 \mathrm{E}-01$ & $9.38 \mathrm{E}-03$ & $8.16 \mathrm{E}-03$ \\
\hline & & & & & & & 199 & 57.6 & $2.46 \mathrm{E}-01$ & $1.08 \mathrm{E}-02$ & $3.80 \mathrm{E}-03$ \\
\hline MB2-11 & QFM & 18.7 & capsule & $\mathrm{T}$ & 1 & & 182 & 16.2 & $3.14 \mathrm{E}-02$ & $2.86 \mathrm{E}-03$ & $9.23 \mathrm{E}-04$ \\
\hline MB2-14 & QFM & 5.7 & capsule & $\mathrm{T}$ & 1 & 484 & 404 & 23.4 & $3.80 \mathrm{E}-02$ & $1.07 \mathrm{E}-03$ & 4.41E-04 \\
\hline MB2-16 & QFM & $\operatorname{var}^{g}$ & capsule & $\mathrm{T}$ & 2 & & 458 & 36.8 & & $8.00 \mathrm{E}-05$ & $1.72 \mathrm{E}-04$ \\
\hline MB2-18 & $\mathrm{IW}+2$ & 231 & capsule & G & 2 & & 490 & 9.3 & $1.04 \mathrm{E}-02$ & $1.32 \mathrm{E}-05$ & $8.84 \mathrm{E}-06$ \\
\hline MB2-17 & $\mathrm{IW}+2$ & 72.4 & capsule & $\mathrm{G}$ & 2 & & 535 & & $1.04 \mathrm{E}-02$ & $2.58 \mathrm{E}-06$ & $4.20 \mathrm{E}-06$ \\
\hline MB2-20 & IW & 231 & wire & G & 2 & & & 27.8 & & 4.37E-05 & \\
\hline MB2-22 & IW & 72.4 & wire & G & 2 & & 407 & 27.8 & & $1.18 \mathrm{E}-05$ & $1.16 \mathrm{E}-05$ \\
\hline MB2-19 & IW & 18.7 & capsule & $\mathrm{T}$ & 2 & & & 22.8 & & 2.07E-05 & $6.21 \mathrm{E}-04$ \\
\hline MB2-21 & IW & 5.7 & capsule & $\mathrm{T}$ & 2 & & & & & $2.07 \mathrm{E}-05$ & $5.79 \mathrm{E}-06$ \\
\hline
\end{tabular}

${ }^{\mathrm{a}}$ Method of controlling $f \mathrm{O}_{2}$ is flowing gases $(\mathrm{G})$ or evacuated tube (T) with solid state buffer.

${ }^{\mathrm{b}}$ Oxide powder batch number.

${ }^{\mathrm{c}}$ Curie temperature.

${ }^{\mathrm{d}}$ Median destructive temperature.

${ }^{\mathrm{e}}$ Median destructive field.

${ }^{\mathrm{f}}$ Saturation remanent magnetization.

${ }^{\mathrm{g}}$ Exponentially varying cooling rate (see text).

${ }^{\mathrm{h}}$ Sample has anomalous texture, mineralogy, and magnetic properties suggesting experimental failure; magnetic properties are therefore not plotted in Figure 6.

$231^{\circ} \mathrm{C} \mathrm{h}^{-1}$ and $18^{\circ} \mathrm{C} \mathrm{h}^{-1}$ are somewhat lower $(340-$ $400^{\circ} \mathrm{C}$ ), consistent with a greater fraction of non-Fe cations.

[64] For many T-type QFM samples, we must rely entirely on the magnetic data to infer the magnetically relevant oxide compositions. Curie and blocking temperature data suggest the presence of a population of (room temperature) remanence-carrying oxides that is on average more magnetite-rich than suggested by the EMP data. All samples have a phase that unblocks at temperatures $>300^{\circ} \mathrm{C}$ (Figure 7), and the available (maximum) Curie temperatures are $>440^{\circ} \mathrm{C}$. Because the EMP analysis was conducted on only the largest crystals, we interpret EMP data as representing the high-temperature, early nucleated phases, with a higher proportion of non-Fe cations. Many of these larger crystals have EMP compositions inconsistent with a magnetically ordered phase at room temperature. Two samples additionally have a phase with low $\left(<300^{\circ} \mathrm{C}\right)$ Curie or blocking temperatures $\left(72^{\circ} \mathrm{C} \mathrm{h}^{-1}\right.$ and $\left.19^{\circ} \mathrm{C} \mathrm{h}^{-1}\right)$. These samples indeed have EMP compositions with high concentrations of $\mathrm{Cr}$, but again with compositions that would be nonmagnetic at room temperature.

[65] Compositional information on the more reduced samples $(<\mathrm{QFM})$ is limited almost exclusively to blocking temperature data. Although these are associated with some uncertainty (see above), the data suggest that T-type samples have oxides that are on average more Fe-rich than the M-type counterparts. Additionally, reduced samples of both compositions appear to have both an ilmenite-rich rhombo- hedral phase and possibly a Ti- and/or Cr-rich spinel phase, neither of which will contribute to the magnetic source layer at crustal temperatures.

[66] Many oxide grains in rapid-cooled M-type experiments are compositionally zoned, with cores rich in $\mathrm{Cr}$ (and to a much lesser extent in $\mathrm{Mg}$ and $\mathrm{Al}$ ). Additionally, morphologic evidence of both diffusion-controlled and interface-controlled crystal growth suggests growth at highly variable rates, possibly in response to episodic nucleation. Conversely, slow cooling is associated with little to no compositional zonation, uniformly euhedral oxide morphology and significantly larger maximum grain sizes, all suggesting that the rate of crystal growth was controlled by the frequency of atom attachment throughout most of the growth period and/or that subsolidus homogenization occurred.

[67] Applying similar inferences to the T-type samples, Cr-rich grains and wide arrays of oxide compositions suggest rapid rates of oxide crystal growth at all cooling rates applied in this study. We speculate that the majority of oxide nucleation occurred at lower temperatures in the T-type than in the M-type samples; lower normative magnetite in the T-type material and the high silicate crystallinity of samples containing interstitial oxides both support this inference. In addition, nucleation and growth at lower temperatures in the T-type runs may also have suppressed subsolidus homogenization and preserved zoning and compositional variety. 


\begin{tabular}{|c|c|c|}
\hline IW & $\mathrm{IW}+2$ & QFM $(I W+3.5)$ \\
\hline 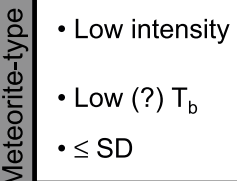 & $\begin{array}{l}\cdot \text { Low-moderate } \\
\text { intensity } \\
\cdot \text { Low (?) } \mathrm{T}_{\mathrm{b}} \\
\cdot \leq \mathrm{SD}\end{array}$ & $\begin{array}{l}\cdot \text { High intensity } \\
\text { - High } \mathrm{T}_{\mathrm{b}} \\
\text {-PSD - MD }\end{array}$ \\
\hline 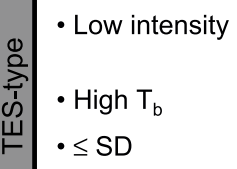 & $\begin{array}{l}\cdot \text { Low intensity } \\
\cdot \text { High } \mathrm{T}_{\mathrm{b}} \\
\cdot \leq \mathrm{SD}\end{array}$ & $\begin{array}{l}\text { - Moderate- } \\
\text { high intensity } \\
\text { - Low-high } \mathrm{T}_{\mathrm{b}} \\
\text { - SD - PSD }\end{array}$ \\
\hline
\end{tabular}

Figure 8. Summary grid showing variation in magnetic properties with major experimental variables. Magnetic properties likely to influence the magnetic anomalies are magnetization intensity, blocking temperature $\left(\mathrm{T}_{\mathrm{b}}\right)$, and domain state (SD, single domain; PSD, pseudo single domain; $\mathrm{MD}$, multidomain). Likelihood that the given magnetic assemblage could result in an intense, stable magnetization, capable of producing the observed Martian magnetic anomalies is shown schematically by the shaded color bar: green is high probability, and white is low probability.

[68] The presence or absence of interstitial oxides is strongly linked to the degree of silicate crystallization in the T-type material (sections 3.1.2 and 3.1.3), indicating that the kinetics of silicate nucleation and growth largely dictate oxide abundance and composition. The T-type material has a much smaller solidification temperature interval, as assessed using the MELTS algorithm [Ghiorso and Sack, 1995]. Higher crystallinity of T-type samples for any given cooling trajectory (section 3.1.3) may reflect the influence of thermodynamic affinity on crystallization rate.

[69] The relative incoherence of mineralogies, phase proportions, and textures with respect to experimental variables in T-type experiments is consistent with the possibility that this composition is more sensitive to factors that influence nucleation kinetics, such as precise thermal history, starting material preparation, container roughness, etc. Plagioclase appears to be particularly prone to nucleation inhibition, a finding consistent with prior basalt dynamic cooling experiments [e.g., Grove, 1978; Grove and Bence, 1979], with the exception of observations by Lesher et al. [1999].

\subsection{Oxide Grain Size}

[70] Samples with a stable single domain grain size are more likely to have a magnetization that will persist through geologic time. For pure magnetite, the upper size limit for coherent, SD behavior is estimated at $\sim 0.05-0.08 \mu \mathrm{m}$ [Dunlop and Özdemir, 1997, and references therein]. For titanomagnetite of composition $\mathrm{Fe}_{2.4} \mathrm{Ti}_{0.6} \mathrm{O}_{4}$ (TM60), it is considerably larger: $\sim 0.2 \mu \mathrm{m}$ [Butler and Banerjee, 1975]. Both SD size estimates are far smaller than the largest grains observable in most of our samples, and indeed, the most slowly cooled samples have hysteresis dominated by MD or pseudo-single-domain (PSD) behavior. On the basis of room temperature hysteresis and low-temperature measurements, however, it is clear that for most other samples there also exists a population that is considerably smaller, spanning into the SP range for T-type samples.

[71] While hysteresis data provide an average grain size, the full grain size distribution likely spans both SD and MD for many samples. It is therefore difficult to estimate how a remanence would decay through time, but we assume that samples with larger average grain size and more MD-like hysteresis behavior will tend to lose more of their remanence through time. We note that magnetic viscosity is commonly observed to be enhanced in coarse-grained rocks relative to fine-grained rocks; however, the theory of viscous magnetization (or demagnetization) has yet to be fully developed for MD grains, and at least one study has found that basalts with MD-sized TM55 do not appear to acquire a viscous magnetization [McClelland et al., 2003].

\subsection{Variable Control on Magnetization}

[72] Keeping in mind the compositional and grain size issues discussed above, we evaluate the role each of our variables plays in controlling the resulting magnetization. Figure 8 provides a summary of variation in magnetic parameters with two of our major experimental variables: oxygen fugacity and major element composition (predominantly $\mathrm{Fe} / \mathrm{Al}$ ratio).

\subsubsection{Oxygen Fugacity}

[73] Within a given composition, $\mathrm{fO}_{2}$ appears to play the dominant role in controlling both oxide abundance and grain size, as well as magnetization, as previously observed [Brachfeld and Hammer, 2006]. Average grain size increases with increasing $f \mathrm{O}_{2}$ over the entire $f \mathrm{O}_{2}$ range investigated in this study, and continuing at least to IW+8.54 [Brachfeld and Hammer, 2006]. There is also a strong correlation between $\mathrm{fO}_{2}$ and TRM (Figure 7), as well as ARM, $M_{r}$ and $M_{s}$, especially for the Fe-rich, M-type samples. As noted in section 3.2.5, this correlation disappears above QFM for M-type samples [Brachfeld and Hammer, 2006], so $\sim$ QFM appears to be an optimum in terms of maximizing intensity while retaining an SD to PSD grain size.

[74] The role of $f \mathrm{O}_{2}$ on oxide composition is more difficult to determine, but it seems that the two bulk compositions may have opposite trends with respect to $\mathrm{fO}_{2}$. The room temperature remanence-bearing phase in M-type samples may become more Fe-poor with decreasing $f \mathrm{O}_{2}$, while that of the T-type samples remains relatively Fe-rich.

\subsubsection{Bulk Composition}

[75] The $\mathrm{Fe} / \mathrm{Al}$ ratio of the sample appears to play a strong role in oxide abundance and grain size. M-type samples with high $\mathrm{Fe} / \mathrm{Al}$ ratio $\left(18 \mathrm{wt} \% \mathrm{FeO}^{*}\right)$ have a higher vol.\% oxides and larger grain size than the low-Fe T-type samples. The magnetization is correspondingly higher in Fe-rich samples, as observed by Gee and Kent [1998]. TRM for the M-type samples is typically 1-2 orders of magnitude higher than that of the T-type samples. However, at QFM the most strongly magnetic T-type sample $\left(72^{\circ} \mathrm{C} \mathrm{h}^{-1}\right)$ is roughly equivalent to that of the M-type samples. Furthermore, the inclusion of highly compatible $\mathrm{Cr}$ in the melt seems to allow the nucleation of oxides at higher temperatures, allowing them to grow larger than in the absence of $\mathrm{Cr}$.

\subsubsection{Cooling Rate}


[76] The effect of cooling rate is most clearly seen within the QFM samples, where a clear trend in average magnetic grain size (or domain state) with cooling rate can be seen. This suggests that while a given $f \mathrm{O}_{2}$ may play a controlling role in the initial intensity of the magnetization, slower cooling rates may allow the grains to grow into an MD state, leading to a decrease in magnetization over geologic time scales.

[77] Properties of the samples cooled with an exponentially decreasing (or variable) cooling rate are inconsistent between the two bulk compositions. The M-type sample most closely resembles the more slowly cooled samples in oxide composition, abundance and magnetic properties. The T-type sample, by contrast, more closely resembles the more rapidly cooled samples in oxide abundance and magnetic grain size. (Compositions are harder to compare in the T-type samples.) Whether the magnetic properties are controlled by high-temperature rapid cooling or lower-temperature slower cooling is relevant as we consider cooling conditions of the bulk Martian crust. This variable cooling path was modeled to simulate the natural cooling path of a conductively cooled lava at $0.25 \mathrm{~m}$ from the surface; even if composed of thin flows, dikes or sills, the bulk of the crust almost certainly cooled more slowly on average than our model cooling path. A composition similar to our M-type composition (where magnetic properties are controlled by the lowtemperature, slower cooling), might therefore be expected to develop even coarser oxides than those in any of our samples. A T-type composition, by contrast, may be able to retain a relatively small grain size even while cooling more slowly, because the magnetic properties would be most strongly influenced by the high-temperature, relatively rapid part of the cooling.

\subsection{Modeling the Anomalies}

[78] To evaluate the possible contribution that each sample type might make to a magnetic anomaly, we construct a simple forward model. We magnetize a block that is square in cross section parallel to the planet's surface and is $400 \mathrm{~km}$ on a side. The scale of the resulting anomalies is roughly that of some of the strong anomalies seen on Mars. Magnetization is calculated using the measured magnetization acquired in a $49 \mu \mathrm{T}$ field (roughly Earth's field) and assuming a density of $2900 \mathrm{~kg} \mathrm{~m}^{-3}$. The magnetization is uniform in direction (vertical down). Intensity is allowed to vary with depth, following the blocking temperature distribution of the sample along a given (linear) geothermal gradient. This is done on a sample-by-sample basis by calculating temperature at a given depth, then finding the corresponding magnetization from the thermal demagnetization data shown in Figures $7 \mathrm{e}$ and $7 \mathrm{f}$. We take the surface temperature of an early, warm Mars to be $273 \mathrm{~K}$ [Fanale et $a l ., 1992]$. The anomaly is calculated at $200 \mathrm{~km}$ altitude, using the method of a surface charge on a polygonal face [Blakely, 1996]. Results are shown (Figure 9) for samples produced under IW +2 to QFM conditions, and for a range of geothermal gradients. We note that a reasonable gradient for early Mars may be $\sim 7-10 \mathrm{~K} \mathrm{~km}^{-1}$ [Arkani-Hamed, 2000; Ruiz et al., 2006], although McGovern et al. [2002] suggest that it may have been $>20 \mathrm{~K} \mathrm{~km}^{-1}$ in places.

[79] The solutions for most of the M-type QFM samples surpass the maximum observed anomalies on Mars for all reasonable geothermal gradients. More reduced samples, which have magnetizations equal to or nearly equal to the QFM samples, also have lower blocking temperatures; this results in thinner source layer and correspondingly decreased anomaly amplitude (dashed lines in Figure 9). Only one T-type sample results in modeled anomalies exceeding the necessary amplitude, and for smaller thermal gradients, which permit a thicker magnetized crust. The TES-type samples also tend to have a more distributed blocking temperature spectrum, which reduces the overall depthintegrated magnetization compared to the meteorite-type samples. We may conclude from this exercise that the more iron-rich meteorite sample can more easily acquire a magnetization both intense enough and with high enough blocking temperatures to produce the strong Martian anomalies, although we cannot entirely rule out a more Earth-like composition.

[80] We note that these modeling results do not include the effects of magnetization in a smaller field, nonvertical magnetization, or viscous decay, all of which will reduce the anomaly amplitude. The effects of a smaller magnetizing field should be linear with applied field. A horizontal magnetization will decrease the anomaly amplitude by approximately one half, and Hood et al. [2007] found that isolated Mars anomalies are consistent with forward models magnetized predominantly in a north-south horizontal plane. The effects of viscous decay are harder to estimate, as discussed above, but if a significant fraction of the remanence is carried by multidomain grains, the decay will likely be considerable.

[81] There are clear tradeoffs in achieving maximum intensity while retaining minimum grain size. Oxygen fugacity must be close to QFM in order to produce enough oxides, but in the M-type samples these oxides rapidly approach MD size as cooling rates approach geologically reasonable values. In the T-type samples, the average grain size remains smaller, but the most intensely magnetized samples have lower than average blocking temperatures, leading to a (relatively) strong magnetization, but a thinner total source layer. Restricting consideration to rapidly cooled materials, the most likely set of conditions to result in an intense, stable remanence may be an Fe-rich crust crystallized under moderately oxidizing (IW +2.75 to QFM) conditions.

\section{Conclusions}

[82] This paper reports on the results of an experimental examination of the magnetic assemblage produced under relatively rapid cooling in basalts of plausible Martian composition. We explore in detail the $f_{2}$ range most commonly found for basaltic meteorites as well as that over which a dramatic change in both oxide abundance and magnetic properties occurs. We systematically evaluate the effects of major element composition, oxygen fugacity $\left(f \mathrm{O}_{2}\right)$, and cooling rate on phase chemistry and magnetic mineralogy, grain size (and domain state), and intensity of remanent magnetization. Figure 8 provides a summary of variation in magnetic parameters with two of our major experimental variables: oxygen fugacity and major element composition (predominantly Fe content).

[83] Our results and conclusions are as follows. 

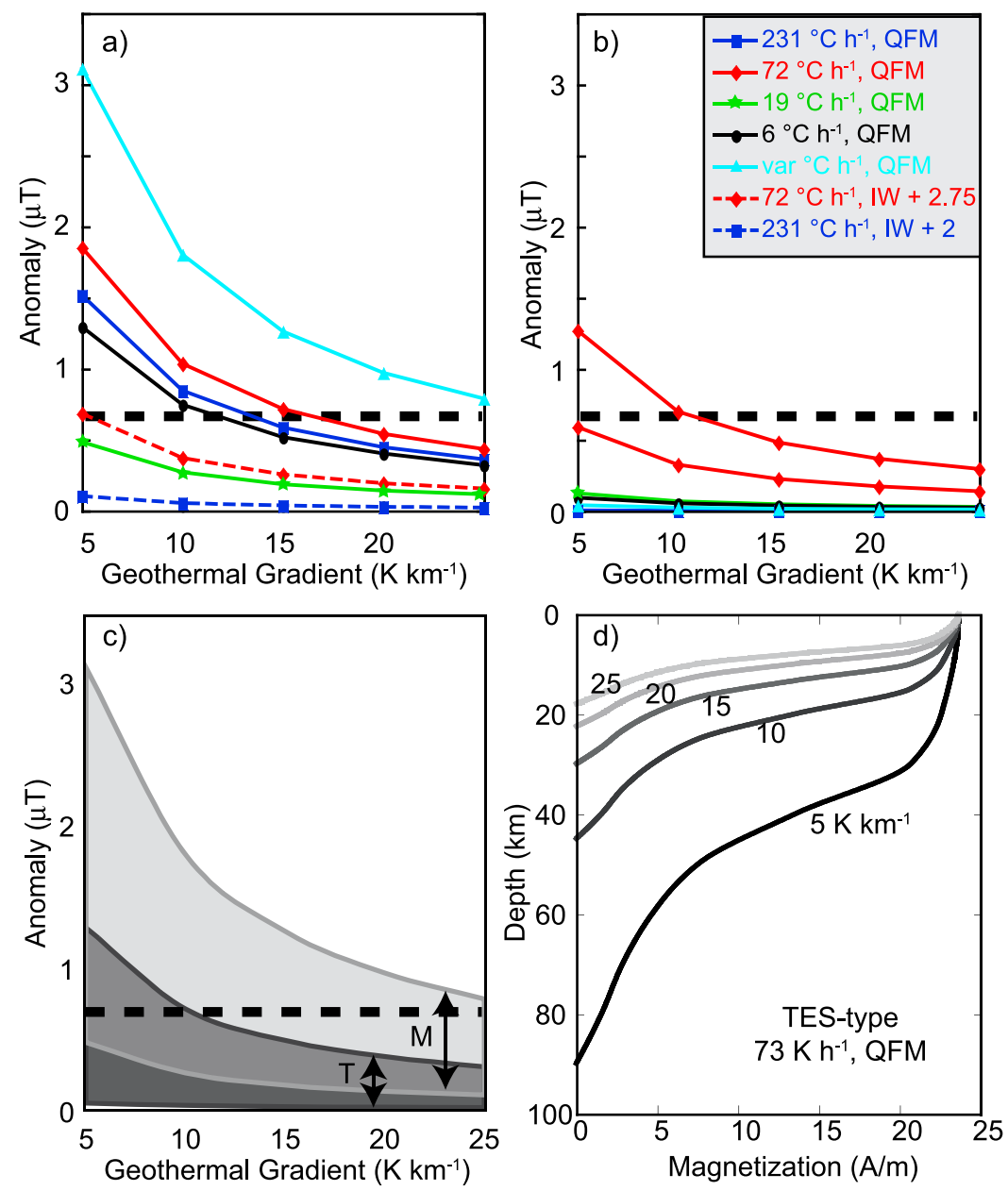

Figure 9. Maximum anomaly predicted at $200 \mathrm{~km}$ altitude for a vertically magnetized body with a $400 \mathrm{~km}$ square cross section (see text for details) over a range of geothermal gradients. Thick dashed line is approximate maximum anomaly observed on Mars at $200 \mathrm{~km}$ altitude. (a) Meteorite-type samples. (b) TES-type samples. (c) Comparison of the range predicted for the two bulk compositions. M designates range for meteorite-type samples; $T$ designates TES-type samples. (d) Example of magnetization versus depth used in the model for one sample (T-type, $73 \mathrm{~K} \mathrm{~h}^{-1}$, QFM) for different geothermal gradients (all shown in $\mathrm{K} \mathrm{km}^{-1}$ ).

[84] 1. The magnetic carrying phase in moderately oxidized (QFM) samples is a spinel-structured oxide with varying amounts of $\mathrm{Cr}, \mathrm{Ti}, \mathrm{Mg}$, and $\mathrm{Al}$. Under more reduced conditions (IW to IW+2) a room temperature remanencebearing phase may be Fe-rich in TES-type samples and Fe-poor in meteorite-type samples.

[85] 2. Oxide compositions and compositional zonation are strongly dependent upon cooling rate in Fe-rich magma, but less so in Al-rich magma, because of differences in crystallization sequence and the kinetics of silicate mineral nucleation and growth.

[86] 3. Oxygen fugacity exerts the primary control on oxide grain size and abundance. Additionally, an Fe-rich melt leads to more, larger oxides, and the presence of $\mathrm{Cr}$ appears to stabilize oxides at higher temperatures, leading to larger oxides. Slower cooling rates also lead to larger average grain size.

[87] 4. Moderately oxidized ( QFM) samples of both compositions can acquire an intense thermal remanent magnetization.
[88] 5. However, a volcanically generated Mars crust of Fe-rich (meteorite-type) composition can more easily produce large magnetic anomalies over a wide range of geothermal gradients.

[89] 6. Increase of grain size into the multidomain range or low blocking temperatures may decrease anomaly amplitude and/or affect long-term stability of remanence.

[90] 7. In rapidly cooled materials, the most likely set of conditions to result in an intense, stable remanence may be an Fe-rich crust crystallized under moderately oxidizing (IW +2 to QFM) conditions.

[91] Acknowledgments. Part of this work was done as a Visiting Fellow at the Institute for Rock Magnetism (IRM) at the University of Minnesota. The IRM is made possible through the Instrumentation and Facilities program of the National Science Foundation, Earth Sciences Division, and by funding from the University of Minnesota. We would like to thank IRM staff and especially Brian Carter-Stiglitz for their generous assistance. Many thanks are due to Mike Jackson and Bruce Moskowitz for many extremely helpful discussions about rock magnetism. We also thank Emilio Herrero-Bervera for use of the University of Hawai'i Paleomagnetics Laboratory. Thanks to John Donovan (University of Oregon) and 
Eric Hellebrand (University of Hawai'i) for assistance with microprobe work. Thank you to David Dunlop and Agnes Kontny whose constructive reviews improved the final manuscript. Work was supported by NASA MFRP award NNG05GL92G to J.E.H. This is SOEST contribution 7655 and IRM contribution 0905 .

\section{References}

Arkani-Hamed, J. (2000), Strength of Martian lithosphere beneath large volcanoes, J. Geophys. Res., 105, 26,713-26,732, doi:10.1029/ $2000 J E 001267$.

Arkani-Hamed, J. (2005), On the possibility of single-domain/pseudo-singledomain magnetic particles existing in the lower crust of Mars: Source of the strong magnetic anomalies, J. Geophys. Res., 110, E12009, doi:10.1029/2005JE002535.

Blakely, R. J. (1996), Potential Theory in Gravity and Magnetic Applications, 441 pp., Cambridge Univ. Press, Cambridge, U. K.

Brachfeld, S. A., and J. Hammer (2006), Rock-magnetic and remanence properties of synthetic Fe-rich basalts: Implications for Mars crusta anomalies, Earth Planet. Sci. Lett., 248, 599-617, doi:10.1016/j.eps1. 2006.04.015.

Brown, L. L., and S. A. McEnroe (2008), Magnetic properties of anorthosites: A forgotten source for planetary magnetic anomalies?, Geophys. Res. Lett., 35, L02305, doi:10.1029/2007GL032522.

Burton, B. P., P. Robinson, S. A. McEnroe, K. Fabian, and T. Boffa Ballaran (2008), A low-temperature phase diagram for ilmenite-rich compositions in the system $\mathrm{Fe}_{2} \mathrm{O}_{3}-\mathrm{FeTiO}_{3}$, Am. Mineral., 93, 1260-1272, doi:10.2138/ am.2008.2690

Butler, R. F., and S. K. Banerjee (1975), Theoretical single-domain grain size range in magnetite and titanomagnetite, J. Geophys. Res., 80 , 4049-4058, doi:10.1029/JB080i029p04049.

Carter-Stiglitz, B., B. Moskowitz, P. Solheid, T. S. Berquó, M. Jackson, and A. Kosterov (2006), Low-temperature magnetic behavior of multidomain titanomagnetites: TM0, TM16, and TM35, J. Geophys. Res., 111, B12S05, doi:10.1029/2006JB004561

Connerney, J. E. P., M. H. Acuña, P. J. Wasilewski, N. F. Ness, H. Rème, C. Mazelle, D. Vignes, R. P. Lin, D. L. Mitchell, and P. A. Cloutier (1999), Magnetic lineations in the ancient crust of Mars, Science, 284 794-798, doi:10.1126/science.284.5415.794.

de Wall, H., A. Kontny, and C. Vahle (2004), Magnetic susceptibility zonation of the melilititic Riedheim dyke (Hegau volcanic field, Germany): Evidence for multiple magma pulses?, J. Volcanol. Geotherm. Res., 131, 143-163, doi:10.1016/S0377-0273(03)00360-3.

Dunlop, D. J., and G. Kletetschka (2001), Multidomain hematite: A source of planetary magnetic anomalies?, Geophys. Res. Lett., 28, 3345-3348, doi:10.1029/2001GL013125.

Dunlop, D. J., and Ö. Özdemir (1997), Rock Magnetism: Fundamentals and Frontiers, 573 pp., Cambridge Univ. Press, Cambridge, U. K.

Fanale, E., P. Fraser, S. E. Postawko, J. B. Pollack, M. H. Carr, and R. O. Pepin (1992), Mars: Epochal climate change and volatile history, in Mars, edited by H. H. Kieffer et al., pp. 1135-1179, Univ. of Ariz. Press, Tucson.

Flower, M. F. J., R. G. Pritchard, G. Brem, J. R. Cann, J. Delany, R. Emmerman, I. L. Gibson, P. J. Oakley, P. T. Robinson, and H.-U. Schmincke (1982), Chemical stratigraphy, Iceland Research Drilling Project Reydarfjordur, eastern Iceland, J. Geophys. Res., 87, 64896510, doi:10.1029/JB087iB08p06489.

Gee, J. S., and D. V. Kent (1998), Magnetic telechemistry and magmatic segmentation on the southern East Pacific rise, Earth Planet. Sci. Lett., 164, 379-385, doi:10.1016/S0012-821X(98)00231-3.

Ghiorso, M. S., and O. Sack (1995), Chemical mass transfer in magmatic processes. IV. A revised and internally consistent thermodynamic mode for the interpolation and extrapolation of liquid-solid equilibria in magmatic systems at elevated temperatures and pressures, Contrib. Mineral. Petrol., 119, 197-212, doi:10.1007/BF00307281.

Grove, T. L. (1978), Cooling histories of Luna 24 very low Ti (VLT) ferrobasalts: An experimental study, Proc. Lunar Planet. Sci. Conf., 9th, 565-584

Grove, T. L., and A. E. Bence (1979), Crystallization kinetics in a multiply saturated basalt magma: An experimental study of Luna 24 ferrobasalt, Proc. Lunar Planet. Sci. Conf., 10th, 439-478.

Gunnlaugsson, H. P., Ö. Helgason, L. Kristjánsson, P. Nørnberg, H. Rasmussen, S. Steinpórsson, and G. Weyer (2006), Magnetic properties of olivine basalt: Application to Mars, Phys. Earth Planet. Inter. 154, 276-289, doi:10.1016/j.pepi.2005.09.012

Haggerty, S. E. (1991), Oxide textures-A mini-atlas, in Oxide Minerals Petrologic and Magnetic Significance, edited by D. H. Lindsley, Rev. Mineral., 25, 129-219.

Hamilton, V. E., M. B. Wyatt, H. Y. McSween Jr., and P. R. Christensen (2001), Analysis of terrestrial and Martian volcanic compositions using thermal emission spectroscopy: 2. Application to Martian surface spectra from the Mars Global Surveyor Thermal Emission Spectrometer, J. Geophys. Res., 106, 14,733-14,746, doi:10.1029/2000JE001353.

Hammer, J. E. (2006), Influence of $\mathrm{fO}_{2}$ and cooling rate on the kinetics and energetics of Fe-rich basalt crystallization, Earth Planet. Sci. Lett., 248 , 618-637, doi:10.1016/j.eps1.2006.04.022.

Hargraves, R. B., J. M. Knudsen, M. B. Madsen, and P. Bertelsen (2001), Finding the right rocks on Mars, Eos Trans. AGU, 82, 292-293.

Harrison, R. J., and A. Putnis (1996), Magnetic properties of the magnetitespinel solid solution: Curie temperatures, magnetic susceptibilities, and cation ordering, Am. Mineral., 81, 375-384.

Herd, C. D. K., L. E. Borg, J. H. Jones, and J. J. Papike (2002), Oxygen fugacity and geochemical variations in the Martian basalts: Implications for Martian basalt petrogenesis and the oxidation state of the upper mantle of Mars, Geochim. Cosmochim. Acta, 66, 2025-2036, doi:10.1016/ S0016-7037(02)00828-1.

Hilliard, J. E. (1968), Measurement of volume in volume, in Quantitative Microscopy, edited by R. T. DeHoff and F. N. Rhines, pp. 45-76, McGraw-Hill, New York.

Hood, L. L., M. C. Richmond, K. P. Harrison, and R. J. Lillis (2007), Eastwest trending magnetic anomalies in the southern hemisphere of Mars Modeling analysis and interpretation, Icarus, 191, 113-131, doi:10.1016/j.icarus.2007.04.025.

Johnson, C. L., and R. J. Phillips (2005), Evolution of the Tharsis region of Mars: Insights from magnetic field observations, Earth Planet. Sci. Lett. 230, 241-254, doi:10.1016/j.eps1.2004.10.038

Johnson, M. C., M. J. Rutherford, and P. C. Hess (1991), Chassigny petrogenesis: Melt compositions, intensive parameters and water contents of Martian magmas, Geochim. Cosmochim. Acta, 55, 349-366, doi:10.1016/0016-7037(91)90423-3.

Kessel, R., J. R. Beckett, and E. M. Stolper (2001), Thermodynamic properties of the Pt-Fe system, Am. Mineral., 86, 1003-1014.

Kilinc, A., I. S. E. Carmichael, M. L. Rivers, and R. O. Sack (1983), The ferric-ferrous ration of natural silicate liquids equilibrated in air, Contrib. Mineral. Petrol., 83, 136-140, doi:10.1007/BF00373086.

Kirkpatrick, R. J. (1981), Kinetics of crystallization of igneous rocks, in $\mathrm{Ki}$ netics of Geochemical Processes, edited by A. Lasaga and R. Kirkpatrick, pp. 321-397, Mineral. Soc. of Am., Washington, D. C.

Kletetschka, G., P. J. Wasilewski, and P. T. Taylor (2000), Hematite vs. magnetite as the signature for planetary magnetic anomalies?, Phys. Earth Planet. Inter, 119, 259-267, doi:10.1016/S0031-9201(00)00141-2.

Kumar, A., and M. S. Bhalla (1984), Source of stable remanence in chromite ores, Geophys. Res. Lett., 11, 177-180, doi:10.1029/GL011i003p00177. Leeman, W. P., D. R. Smith, W. Hildreth, Z. Palacz, and N. Rogers (1990), Compositional diversity of late Cenozoic basalts in a transect across the southern Washington cascades: Implications for subduction zone magmatism, J. Geophys. Res., 95, 19,561-19,582, doi:10.1029/JB095iB12p19561.

Lesher, C. E., K. V. Cashman, and J. D. Mayfield (1999), Kinetic controls on crystallization of Tertiary North Atlantic basalt and implications for the emplacement and cooling history of lava at Site 989, southeast Greenland rifted margin, Proc. Ocean Drill. Program Sci. Results, 163, 135-148.

McClelland, E., L. Bardot, P. Erwin, and N. Charnley (2003), Absence of natural viscous remanent magnetization in multidomain high-titanium magnetites: Evidence for domain-wall interactions, Geophys. J. Int. 154, 104-116, doi:10.1046/j.1365-246X.2003.01953.x.

McEnroe, S. A., R. J. Harrison, P. Robinson, and F. Langenhorst (2002), Nanoscale haematite-ilmenite lamellae in massive ilmenite rock: An example of "lamellar magnetism" with implications for planetary magnetic anomalies, Geophys. J. Int., 151, 890-912, doi:10.1046/j.1365246X.2002.01813.x.

McGovern, P. J., S. C. Solomon, D. E. Smith, M. T. Zuber, M. Simons, M. A. Wieczorek, R. J. Phillips, G. A. Neumann, O. Aharonson, and J. W. Head (2002), Localized gravity/topography admittance and correlation spectra on Mars: Implications for regional and global evolution, J. Geophys. Res., 107(E12), 5136, doi:10.1029/2002JE001854.

McSween, H. Y., Jr. (2007), Mars, in Treatise on Geochemistry, edited by H. D. Holland and K. K. Turekian, pp. 1-27, doi:10.1016/B0-08043751-6/01072-0, Elsevier, Amsterdam

McSween, H. Y., et al. (2006), Alkaline volcanic rocks from the Columbia Hills, Gusev crater, Mars, J. Geophys. Res., 111, E09S91, doi:10.1029/ 2006JE002698.

Moskowitz, B. M., R. B. Frankel, and D. A. Bazylinski (1993), Rock magnetic criteria for the detection of biogenic magnetite, Earth Planet. Sci. Lett., 120, 283-300, doi:10.1016/0012-821X(93)90245-5.

Moskowitz, B. M., M. Jackson, and C. Kissel (1998), Low-temperature magnetic behavior of titanomagnetites, Earth Planet. Sci. Lett., 157, 141-149, doi:10.1016/S0012-821X(98)00033-8

Nekvasil, H., J. Filiberto, F. M. McCubbin, and D. H. Lindsley (2007) Alkalic parental magmas for chassignites?, Meteorit. Planet. Sci., 42 , 979-992. 
Nekvasil, H., F. McCubbin, A. Harrington, S. Elardo, and D. Lindsley (2009), Linking the Chassigny meteorite and the Martian surface rock Backstay: Insights into igneous crustal differentiation processes on Mars, Meteorit. Planet. Sci., 44, 853-869.

Nimmo, F. (2000), Dike intrusion as a possible cause of linear Martian magnetic anomalies, Geology, 28, 391-394, doi:10.1130/00917613(2000)28<391:DIAAPC $>2.0 . \mathrm{CO} ; 2$

Radhakrishna Murthy, I. V., and S. K. G. Krishnamacharyulu (1994), Identification of NRM carriers in chromite ores by alternating field and thermal demagnetization studies, Curr. Sci., 66, 373-375.

Robbins, M., G. K. Wertheim, R. C. Sherwood, and D. N. E. Buchanan (1971), Magnetic properties and site distributions in the system $\mathrm{FeCr}_{2} \mathrm{O}_{4}$ $\mathrm{Fe}_{3} \mathrm{O}_{4}\left(\mathrm{Fe}^{2+} \mathrm{Cr}_{2-\mathrm{x}} \mathrm{Fe}_{\mathrm{x}}^{3+} \mathrm{O}_{4}\right)$, J. Phys. Chem. Solids, 32, 717-729, doi:10.1016/S0022-3697(71)80412-2.

Rochette, P., J. Gattacceca, V. Chevrier, V. Hoffmann, J.-P. Lorand, M. Funaki, and R. Hochleitner (2005), Matching Martian crustal magnetization and magnetic properties of Martian meteorites, Meteorit. Planet. Sci., 40, 529-540.

Ruiz, J., P. J. McGovern, and R. Tejero (2006), The early thermal and magnetic state of the cratered highlands of Mars, Earth Planet. Sci. Lett. 241, 2-10, doi:10.1016/j.epsl.2005.10.016.

Schmidbauer, E., and P. W. Readman (1982), Low temperature magnetic properties of Ti-rich Fe-Ti spinels, J. Magn. Magn. Mater., 27, 114-118, doi:10.1016/0304-8853(82)90290-6.

Scott, E. R. D., and M. Fuller (2004), A possible source for the Martian crustal magnetic field, Earth Planet. Sci. Lett., 220, 83-90, doi:10.1016/ S0012-821X(04)00032-9.

Shaw, H. (1972), Viscosities of magmatic silicate liquids: An empirical method of prediction, Am. J. Sci., 272, 870-889.

Stanley, S., L. Elkins-Tanton, M. T. Zuber, and E. M. Parmentier (2008), Mars' paleomagnetic field as the result of a single-hemisphere dynamo, Science, 321, 1822-1825, doi:10.1126/science.1161119.

Stevenson, D. J. (2001), Mars' core and magnetism, Nature, 412, 214-219, doi:10.1038/35084155.
Treiman, A. H. (1993), The parent magma of the Nakhla (SNC) meteorite, inferred from magmatic inclusions, Geochim. Cosmochim. Acta, 57 4753-4767, doi:10.1016/0016-7037(93)90198-6.

Turcotte, D. L., and G. Schubert (2002), Geodynamics, Cambridge Univ. Press, Cambridge, U. K.

Van de Moortèle, B., B. Reynard, P. Rochette, M. Jackson, P. Beck, P. Gillet, P. F. McMillan, and C. A. McCammon (2007), Shockinduced metallic iron nanoparticles in olivine-rich Martian meteorites, Earth Planet. Sci. Lett., 262, 36-49.

Wadhwa, M. (2008), Redox conditions on small bodies, the Moon and Mars, Rev. Mineral. Geochem., 68, 493-510, doi:10.2138/ rmg.2008.68.17.

Weiss, B. P., H. Vali, F. J. Baudenbacher, J. L. Kirschvink, S. T. Stewart, and D. L. Shuster (2002), Records of an ancient Martian magnetic field in ALH84001, Earth Planet. Sci. Lett., 201, 449-463, doi:10.1016/S0012821X(02)00728-8.

Worm, H.-U. (1998), On the superparamagnetic-stable single domain transition for magnetite, and frequency dependence of susceptibility, Geophys. J. Int., 133, 201-206, doi:10.1046/j.1365-246X.1998.1331468.x.

Worm, H.-U., and M. Jackson (1999), The superparamagnetism of Yucca Mountain Tuff, J. Geophys. Res., 104, 25,415-25,425, doi:10.1029/ 1999JB900285.

Yu, Y., and J. S. Gee (2005), Spinel in Martian meteorite SaU 008: Implications for Martian magnetism, Earth Planet. Sci. Lett., 232, 287-294, doi:10.1016/j.epsl.2004.12.015

Zhong, S., and J. H. Roberts (2003), On the support of the Tharsis Rise on Mars, Earth Planet. Sci. Lett., 214, 1-9, doi:10.1016/S0012821X(03)00384-4.

J. A. Bowles, Institute for Rock Magnetism, University of Minnesota, 289 Shepherd Laboratories, 100 Union Street SE, Minneapolis, MN 55455, USA. (jbowles@umn.edu)

S. A. Brachfeld, Department of Earth and Environmental Studies, Montclair State University, Upper Montclair, NJ 07043, USA.

J. E. Hammer, Department of Geology and Geophysics, University of Hawai'i at Mānoa, 1680 East-West Road, Honolulu, HI 96822, USA. 